\title{
Acid-Modulated Synthesis of High Surface Area Amine-Functionalized MIL-101(Cr) Nanoparticles for $\mathrm{CO}_{2}$ Separations
}

Gang Han,$^{\dagger}$ Katherine Mizrahi Rodriguez, ${ }^{\ddagger}$ Qihui Qian ${ }^{\dagger}$ and Zachary P. Smith ${ }^{*}{ }^{\dagger}$

${ }^{\dagger}$ Department of Chemical Engineering, Massachusetts Institute of Technology, 77

Massachusetts Avenue, Cambridge, Massachusetts 02139, United States

$\$$ Department of Materials Science and Engineering, Massachusetts Institute of Technology,

77 Massachusetts Avenue, Cambridge, Massachusetts 02139, United States

* Corresponding author

Tel: +1 6177154503. Fax: +1 6172588224. Email: zpsmith@mit.edu 


\section{EXPERIMENTAL AND CHARACTERIZATION METHODS}

\subsection{Materials and Chemicals}

Chromium nitrate nonahydrate $\left(\mathrm{Cr}\left(\mathrm{NO}_{3}\right)_{3} \cdot 9 \mathrm{H}_{2} \mathrm{O}, 99.0 \%\right)$, 2-aminoterephthalic acid $\left(\mathrm{H}_{2} \mathrm{~N}-\right.$ $\mathrm{H}_{2} \mathrm{BDC}$, 99.0\%), and terephthalic acid $\left(\mathrm{H}_{2} \mathrm{BDC}, 99.0 \%\right)$ were purchased from Sigma-Aldrich and used as received. Hydrochloric acid ( $\mathrm{HCl}, 37 \%$, Sigma-Aldrich), nitric acid $\left(\mathrm{HNO}_{3}, 65 \%\right.$, Merck), acetic acid $\left(\mathrm{CH}_{3} \mathrm{COOH}, 99.7 \%\right.$, Sigma-Aldrich), trifluoroacetic acid $\left(\mathrm{CF}_{3} \mathrm{COOH}, 99 \%\right.$, Alfa Aesar), hydrofluoric acid (HF, 38-40\%, Merck), and stearic acid (>97\%, Merck) were also used as received. Deionized water was used as the solvent for the syntheses. Dimethylformamide (DMF, 99.8\%) and ethanol (EtOH, 99.9\%) obtained from VWR were used as the solvents for particle purification.

\subsection{Synthesis of MIL-101(Cr)-NH2}

The amine-functionalized MIL-101(Cr) nanoparticles, MIL-101(Cr)-NH2, were hydrothermally synthesized in water using different acidic modulators. In a typical synthesis, $\mathrm{Cr}\left(\mathrm{NO}_{3}\right)_{3} \cdot 9 \mathrm{H}_{2} \mathrm{O}(252.1 \mathrm{mg}, 0.63 \mathrm{mmol})$ and $\mathrm{H}_{2} \mathrm{~N}-\mathrm{H}_{2} \mathrm{BDC}(114.1 \mathrm{mg}, 0.63 \mathrm{mmol})$ were mixed in $10 \mathrm{~mL}$ deionized water and then sonicated at room temperature for $2 \mathrm{~min}$, resulting in a violet-colored suspension. After that, a certain amount of acid was added into the mixture and sonicated for another $1 \mathrm{~h}$. The resulting mixture was then transferred into a $30 \mathrm{~mL}$ Teflon-lined stainless steel autoclave and heated at different temperatures for different times under autogenous pressure without stirring. The detailed reaction conditions for each synthesis are summarized in Table S1. After the reaction, the autoclave was left in the oven to naturally cool down to room temperature. The green precipitates were collected by centrifugation (11000 rpm, $120 \min )$. 


\subsection{Synthesis of MIL-101(Cr)}

The parent MIL-101(Cr) benchmark was hydrothermally synthesized via an HF-free procedure reported in our previous work. ${ }^{1}$ In a typical reaction, $\mathrm{Cr}\left(\mathrm{NO}_{3}\right)_{3} \cdot 9 \mathrm{H}_{2} \mathrm{O}(2.0 \mathrm{~g}, 5.0 \mathrm{mmol})$ and $\mathrm{H}_{2} \mathrm{BDC}(0.83 \mathrm{~g}, 5.0 \mathrm{mmol})$ were dispersed in $20 \mathrm{~mL}$ deionized water and then sonicated at room temperature for $1 \mathrm{~h}$. The mixture was then transferred into a $30 \mathrm{~mL}$ Teflon-lined autoclave and kept at $218{ }^{\circ} \mathrm{C}$ for $15 \mathrm{~h}$ under autogenous pressure. After the reaction, the autoclave was left to cool down naturally to room temperature and the green precipitates were collected by centrifugation (11000 rpm, $60 \mathrm{~min})$.

\subsection{Purification of MOF Particles}

A comprehensive washing procedure was applied to purify the as-synthesized MIL-101(Cr)$\mathrm{NH}_{2}$ and MIL-101(Cr) nanoparticles. After each synthesis, the green precipitates were collected by centrifugation and then washed with $20 \mathrm{~mL}$ deionized water to remove any unreacted chromium salt and water-soluble additives. The green particles were subsequently washed with DMF 3 times at $120{ }^{\circ} \mathrm{C}$ to remove the unreacted carboxylic acid ligand after which the products were further washed with ethanol 3 times. For each washing step, $20 \mathrm{~mL}$ of fresh DMF or ethanol was used to disperse the particles and the resulting suspension was indirectly sonicated for $12 \mathrm{~h}$ to remove unreacted ligand and modulator remaining in the pores. The solid product was isolated by centrifugation (11,000 rpm and $120 \mathrm{~min}$ for MIL-101(Cr)-NH 2 and 11,000 rpm and $60 \mathrm{~min}$ for MIL-101(Cr)). Finally, the purified particles were vacuum dried at $130{ }^{\circ} \mathrm{C}$ for $12 \mathrm{~h}$ and then activated at $150{ }^{\circ} \mathrm{C}$ for $24 \mathrm{~h}$ before characterization.

\subsection{Characterization}

Powder X-ray diffraction (XRD) analysis was conducted on a Rigaku Smartlab Multipurpose $\mathrm{X}$-ray diffractometer with $\mathrm{Cu}-\mathrm{K} \alpha$ radiation $(\lambda=1.5406 \AA)$ at a voltage of $45 \mathrm{kV}$ and $200 \mathrm{~mA}$. 
The XRD patterns were scanned over the angular range of $2-40^{\circ}(2 \theta)$ with a step size of $0.1^{\circ}$. Transmission electron microscopy (TEM) images were acquired on an FEI Tecnai (G2 Spirit TWIN) multipurpose digital system operating at $120 \mathrm{kV}$. TEM samples were prepared by placing drops of the particle suspension in ethanol on lacey carbon-coated 200 mesh copper grids (Electron Microscopy Sciences). A Zeiss Merlin high-resolution scanning electron microscope (SEM) was used for particle morphological analysis. SEM samples were sputtercoated with a $\sim 6 \mathrm{~nm}$ layer of gold/palladium alloy using a Desk II cold sputter unit (Denton Vacuum LLC). The thermal stability analysis of the particles was conducted on a TGA 550 thermogravimetric analyzer in air at a heating rate of $10^{\circ} \mathrm{C} / \mathrm{min}$. The Fourier transform infrared (FTIR) spectra in the range of $400-4000 \mathrm{~cm}^{-1}$ were collected on a Thermo Fisher FTIR6700 spectrometer in ATR mode using a resolution of $4 \mathrm{~cm}^{-1}$ with 32 scans. The elemental and chemical spectroscopic analysis was obtained by X-ray photoelectron spectroscopy (XPS) using a ULVAC-PHI Versaprobe II instrument with a monochromic Al-Ka X-ray source $(\mathrm{h} v=1486.6 \mathrm{eV})$. The $\mathrm{X}$-ray source power was $50 \mathrm{~W}$ and the beam spot size was $200 \mu \mathrm{m}$. Survey spectra and high energy resolution spectra were taken with a pass energy of $187.85 \mathrm{eV}$ and $23.50 \mathrm{eV}$, respectively. All spectra were obtained with a photoelectron take-off angle of $45.0^{\circ}$. The number-averaged particle size distribution was obtained from dynamic light scattering (DLS) analysis at $25^{\circ} \mathrm{C}$ with a Zetasizer Nano S90 (Marvern). The particles were dispersed in ethanol with ultralow sample loading, and the highly diluted suspension was sonicated before the DLS measurements. The nitrogen adsorption-desorption isotherms were measured on a Micromeritics 3Flex apparatus at $77 \mathrm{~K}$, and the Brunauer-Emmett-Teller (BET) surface area was calculated over the range of relative pressures between 0.05 and 0.20. All BET tests were run in triplicate and standard deviations are reported from three independent experiments. Single and representative BET isotherms are presented for figures in the text. 


\subsection{Gas Adsorption Measurements}

The $\mathrm{CO}_{2}, \mathrm{CH}_{4}$, and $\mathrm{N}_{2}$ adsorption isotherms of MOF nanoparticles were measured using gases of ultrahigh purity from Airgas on a Micromeritics 3Flex apparatus at different temperatures and pressures. In a typical measurement, a vacuum-dried sample ( 100-150 mg) was loaded into the glass analysis tube, which was then transferred to a degas port to be heated and evacuated, including an initial ramp to $100{ }^{\circ} \mathrm{C}$ at $10{ }^{\circ} \mathrm{C} / \mathrm{min}$, a hold at $100{ }^{\circ} \mathrm{C}$ for $30 \mathrm{~min}$, and a final ramp to $150{ }^{\circ} \mathrm{C}$ at $10{ }^{\circ} \mathrm{C} / \mathrm{min}$, where the temperature was held for $12 \mathrm{~h}$. After degassing, the sample tube was backfilled with $\mathrm{N}_{2}$ and then transferred to the analysis port. During each test, the equilibrium time for measuring each pressure point was set for at least $300 \mathrm{~s}$. After each $300 \mathrm{~s}$ hold, if pressure changed by more than 5\%, the sample was allowed to equilibrate for an additional $300 \mathrm{~s}$. This process was repeated until equilibrium was reached.

The relationship between adsorption amount and gas bulk pressure was obtained using a Langmuir-Freundlich fit for the adsorption isotherms: ${ }^{2-5}$

$$
\frac{N}{N_{m}}=\frac{B \times P^{(1 / t)}}{1+B \times P^{(1 / t)}}
$$

where $N$ represents the uptake amount at a certain equilibrium pressure $(P), N_{m}$ is the theoretical maximum, and both $B$ and $t$ are the equation constants. The obtained adjusted $\mathrm{R}^{2}$ values for all of these fits were larger than 0.999 . To obtain accurate pressure, $P$, corresponding to the same adsorption amount, the above equation can be rearranged to:

$$
\mathrm{P}=\left(\frac{N / N_{m}}{B-B \times N / N_{M}}\right)^{t}
$$

The single gas ideal selectivity $(\alpha)$ of gas $A$ over gas $B$ at a certain pressure was calculated as:

$$
\alpha_{A / B}=\frac{N_{A}}{N_{B}}
$$

The isosteric heat $\left(Q_{s t}\right)$ values for $\mathrm{CO}_{2}$ adsorption were calculated using the ClausiusClapeyron equation: ${ }^{4,5}$

$$
\frac{d \ln P}{d(1 / T)}=-\frac{Q_{s t}}{R}
$$


The adsorption selectivity factor $\left(S_{a d s}\right)$ for binary gas mixtures of $\mathrm{CO}_{2}$ and $\mathrm{N}_{2}$ was obtained using ideal adsorbed solution theory (IAST): ${ }^{5}$

$$
S_{a d s}=\frac{q_{C O_{2}} / q_{N_{2}}}{p_{\mathrm{CO}_{2}} / p_{N_{2}}}
$$

where $q_{i}$ is the uptake and $p_{i}$ is the partial pressure of $i$ component.

Post-combustion flue gas is generally released at a temperature of $323 \mathrm{~K}$ and a total pressure of approximately 1 bar with a composition of $0.15 \% \mathrm{CO}_{2}, 0.75 \% \mathrm{~N}_{2}$, and $10 \%$ other minor components. ${ }^{5}$ As a result, an idealized flue gas mixture composed of 0.15 bar $\mathrm{CO}_{2}$ and $0.85 \mathrm{bar}$ $\mathrm{N}_{2}$ was used in this study to calculate the IAST selectivities at $323 \mathrm{~K}$. 

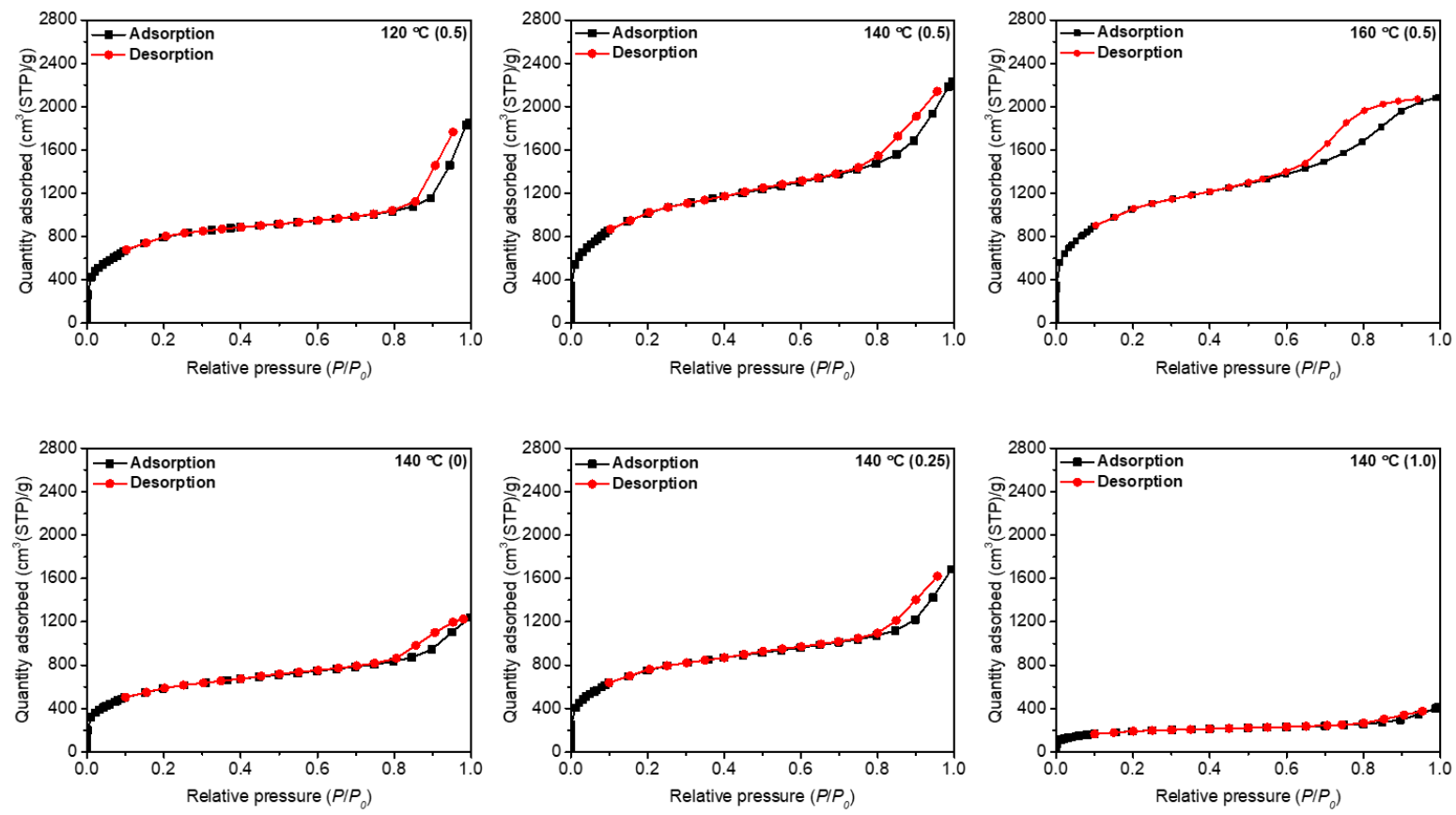

Figure S1. $\mathrm{N}_{2}$ adsorption-desorption isotherms at $77 \mathrm{~K}$ for MIL-101(Cr)- $\mathrm{NH}_{2}$ synthesized at different temperatures for $24 \mathrm{~h}$ using an $\mathrm{HCl}$ modulator with an $\mathrm{HCl} / \mathrm{H}_{2} \mathrm{~N}-\mathrm{H}_{2} \mathrm{BDC}$ molar ratio of 0.5 (top), and MIL-101(Cr)- $\mathrm{NH}_{2}$ synthesized at $140{ }^{\circ} \mathrm{C}$ for $24 \mathrm{~h}$ using an $\mathrm{HCl}$ modulator with different $\mathrm{HCl} / \mathrm{H}_{2} \mathrm{~N}-\mathrm{H}_{2} \mathrm{BDC}$ molar ratios (bottom). Molar ratios are labeled in parentheses. 

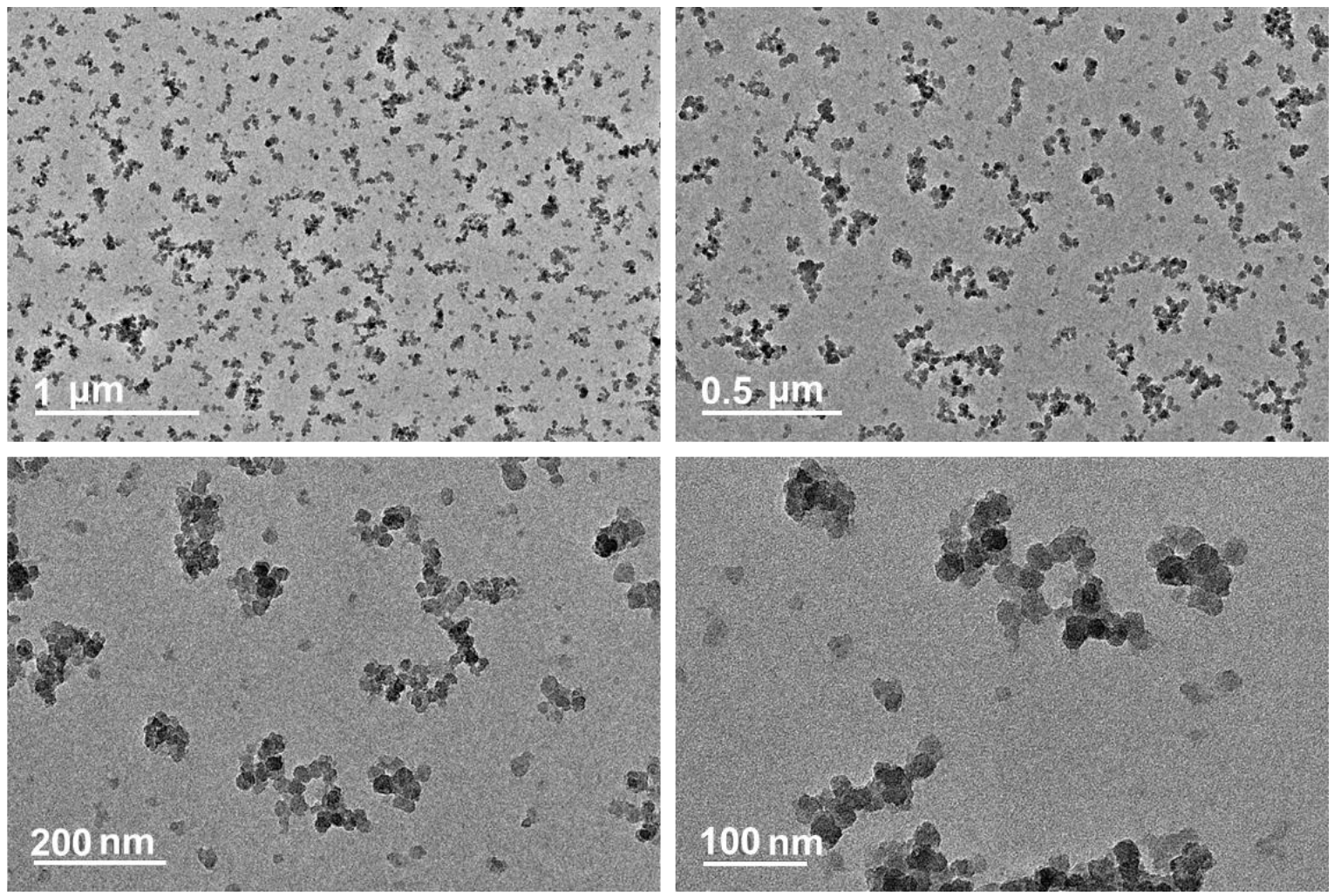

Figure S2. TEM images under different magnifications of MIL-101(Cr)-NH2 synthesized at $120{ }^{\circ} \mathrm{C}$ for $24 \mathrm{~h}$ using an $\mathrm{HCl}$ modulator with an $\mathrm{HCl} / \mathrm{H}_{2} \mathrm{~N}-\mathrm{H}_{2} \mathrm{BDC}$ molar ratio of 0.5. 

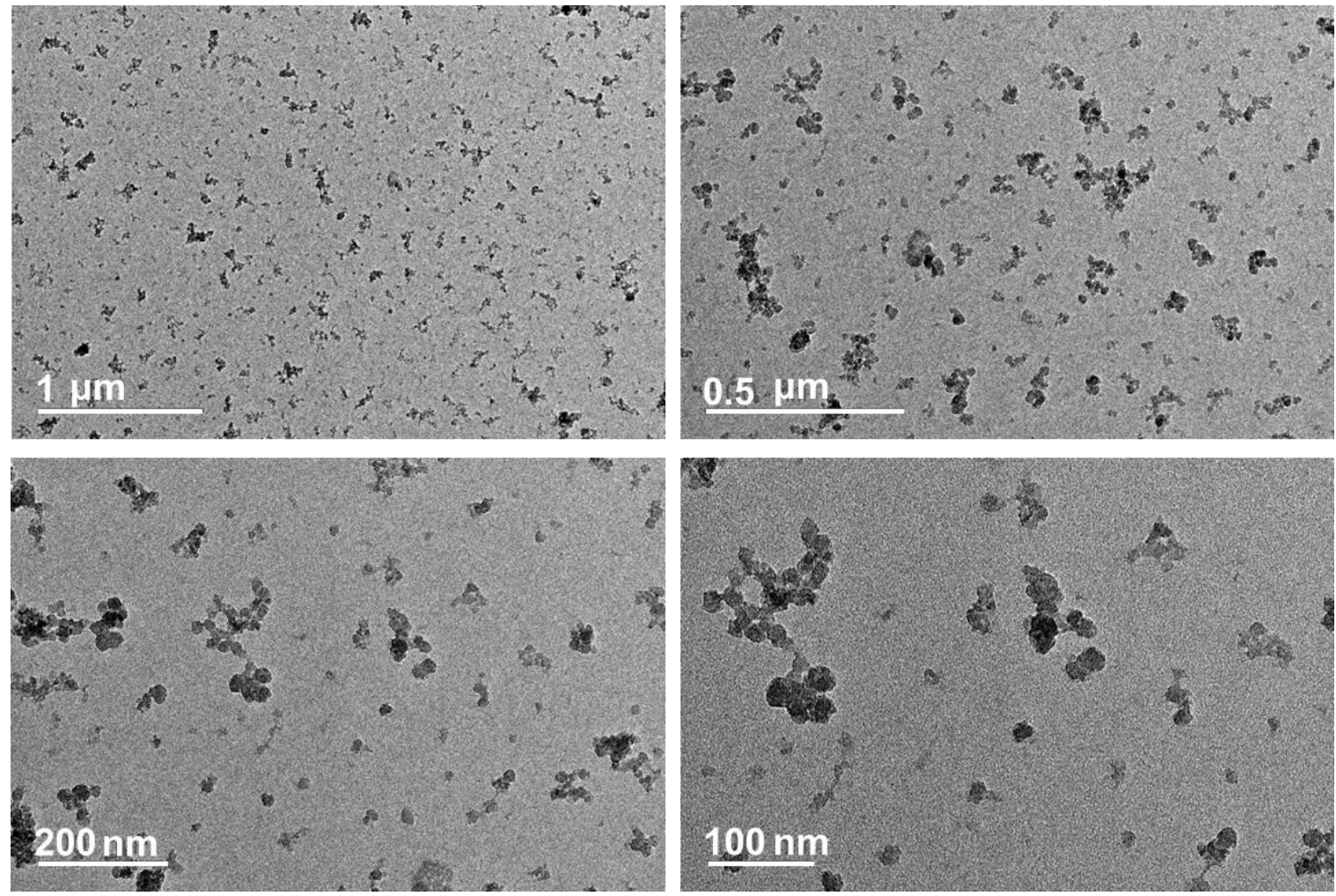

Figure S3. TEM images under different magnifications of MIL-101(Cr)- $\mathrm{NH}_{2}$ synthesized at $140{ }^{\circ} \mathrm{C}$ for $24 \mathrm{~h}$ using an $\mathrm{HCl}$ modulator with an $\mathrm{HCl} / \mathrm{H}_{2} \mathrm{~N}-\mathrm{H}_{2} \mathrm{BDC}$ molar ratio of 0.5 . 

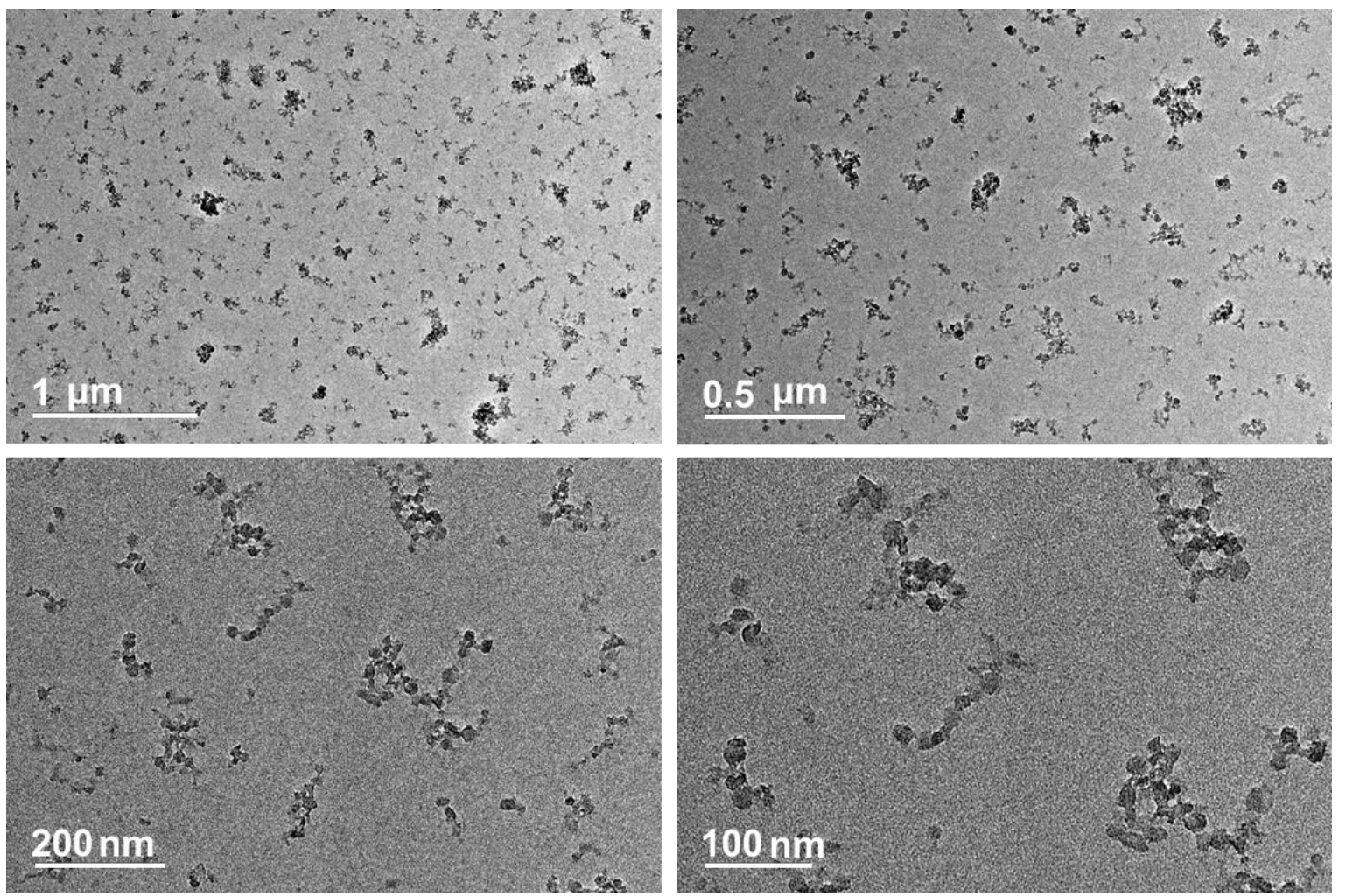

Figure S4. TEM images under different magnifications of MIL-101(Cr)- $\mathrm{NH}_{2}$ nanoparticles synthesized at $160{ }^{\circ} \mathrm{C}$ for $24 \mathrm{~h}$ using an $\mathrm{HCl}$ modulator with an $\mathrm{HCl} / \mathrm{H}_{2} \mathrm{~N}-\mathrm{H}_{2} \mathrm{BDC}$ molar ratio of 0.5 . 
(a)

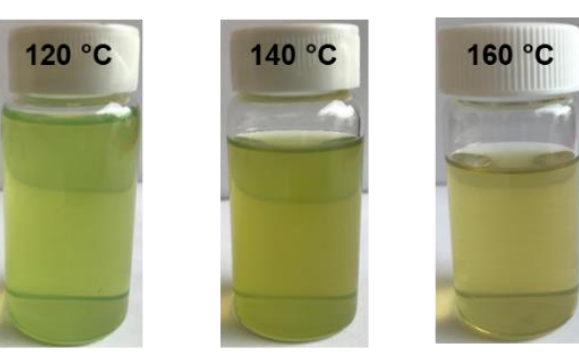

(b)

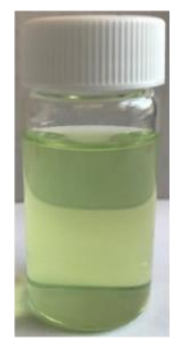

$0 \& 24 h$
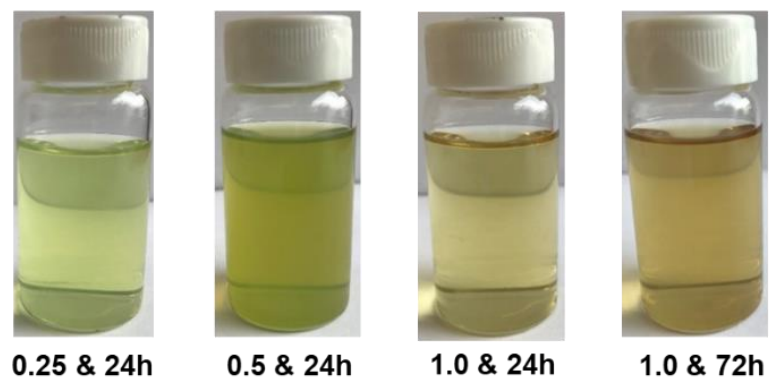

Figure S5. Ethanol suspension of MIL-101(Cr)- $\mathrm{NH}_{2}$ nanoparticles synthesized at different temperatures for $24 \mathrm{~h}$ using an $\mathrm{HCl}$ modulator with an $\mathrm{HCl} / \mathrm{H}_{2} \mathrm{~N}-\mathrm{H}_{2} \mathrm{BDC}$ molar ratio of 0.5 (top), and MIL-101(Cr)- $\mathrm{NH}_{2}$ synthesized at $140{ }^{\circ} \mathrm{C}$ for $24 \mathrm{~h}$ and $72 \mathrm{~h}$ with different $\mathrm{HCl} / \mathrm{H}_{2} \mathrm{~N}$ $\mathrm{H}_{2} \mathrm{BDC}$ molar ratios (bottom). 

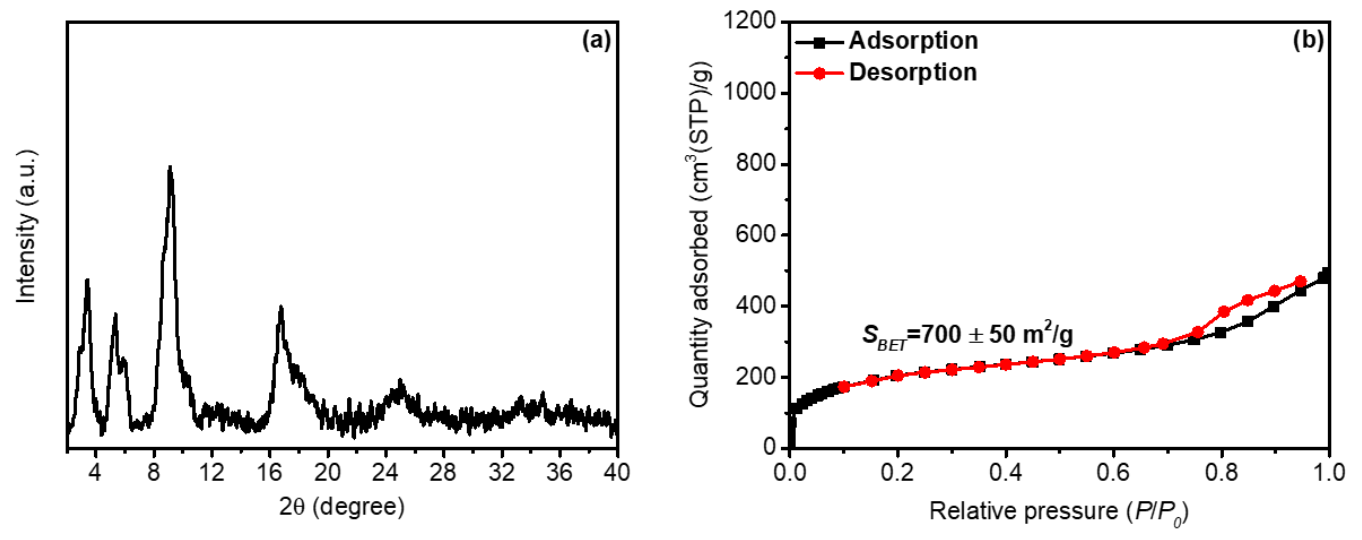

Figure S6. Powder XRD pattern (a) and $\mathrm{N}_{2}$ adsorption-desorption isotherms at $77 \mathrm{~K}$ with the calculated BET surface area (b) of MIL-101(Cr)- $\mathrm{NH}_{2}$ synthesized at $140{ }^{\circ} \mathrm{C}$ for $72 \mathrm{~h}$ using an $\mathrm{HCl}$ modulator with an $\mathrm{HCl} / \mathrm{H}_{2} \mathrm{~N}-\mathrm{H}_{2} \mathrm{BDC}$ molar ratio of 1.0. 

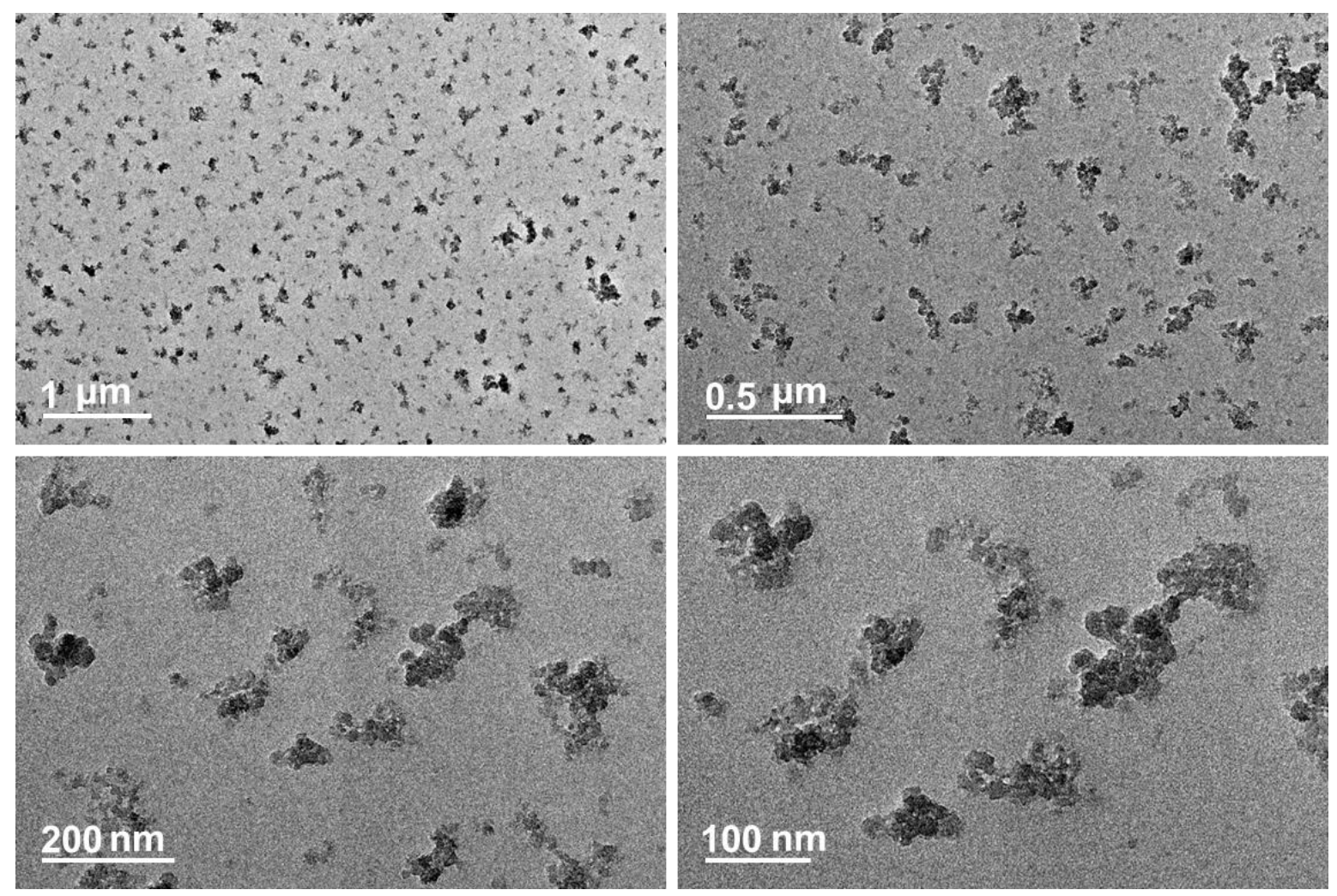

Figure S7. TEM images under different magnifications of MIL-101(Cr)- $\mathrm{NH}_{2}$ nanoparticles synthesized at $140{ }^{\circ} \mathrm{C}$ for $24 \mathrm{~h}$ in pure water without using any modulator. ${ }^{1}$ 

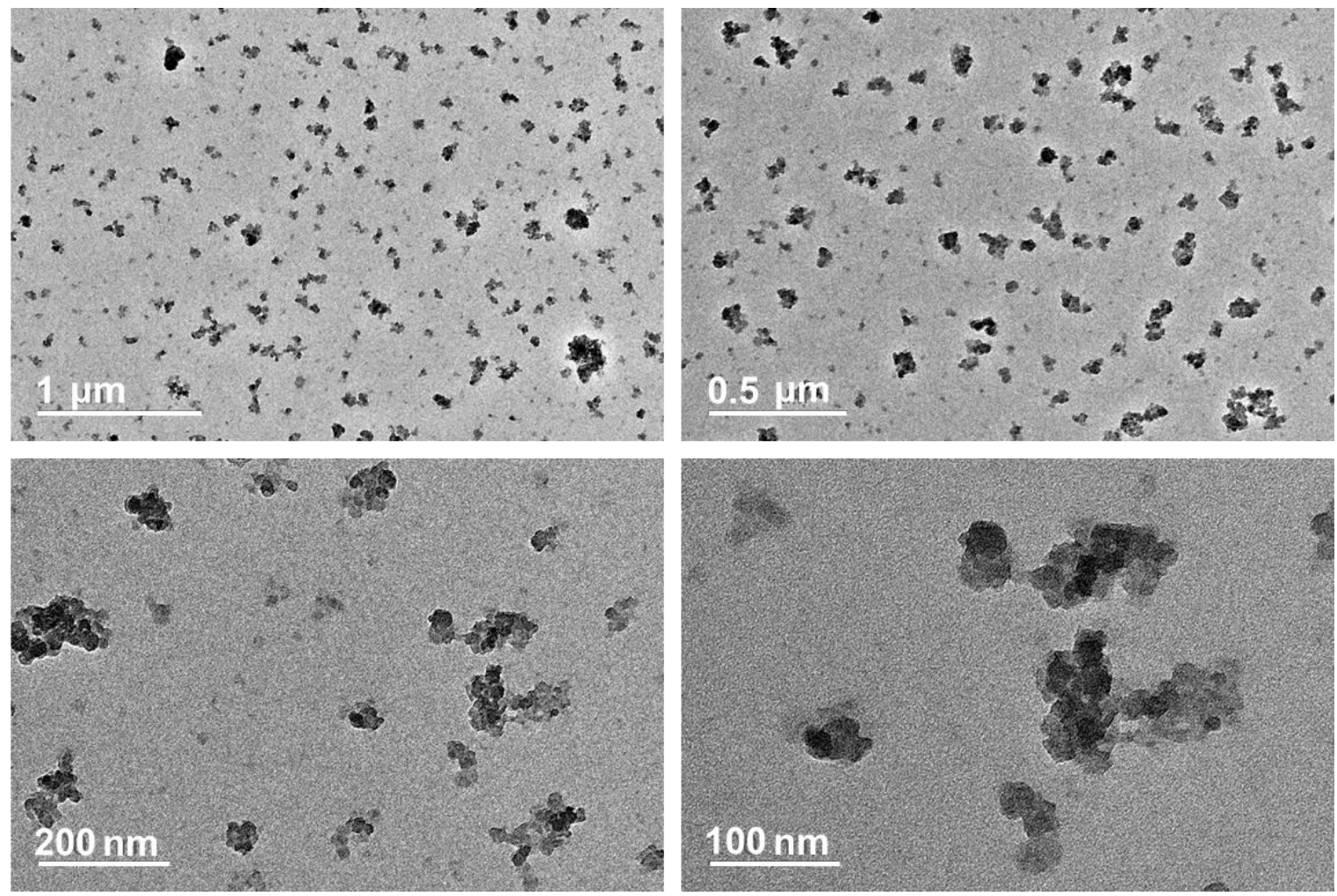

Figure S8. TEM images under different magnifications of MIL-101(Cr)- $\mathrm{NH}_{2}$ nanoparticles synthesized at $140{ }^{\circ} \mathrm{C}$ for $24 \mathrm{~h}$ using an $\mathrm{HCl}$ modulator with an $\mathrm{HCl} / \mathrm{H}_{2} \mathrm{~N}-\mathrm{H}_{2} \mathrm{BDC}$ molar ratio of 0.25 . 

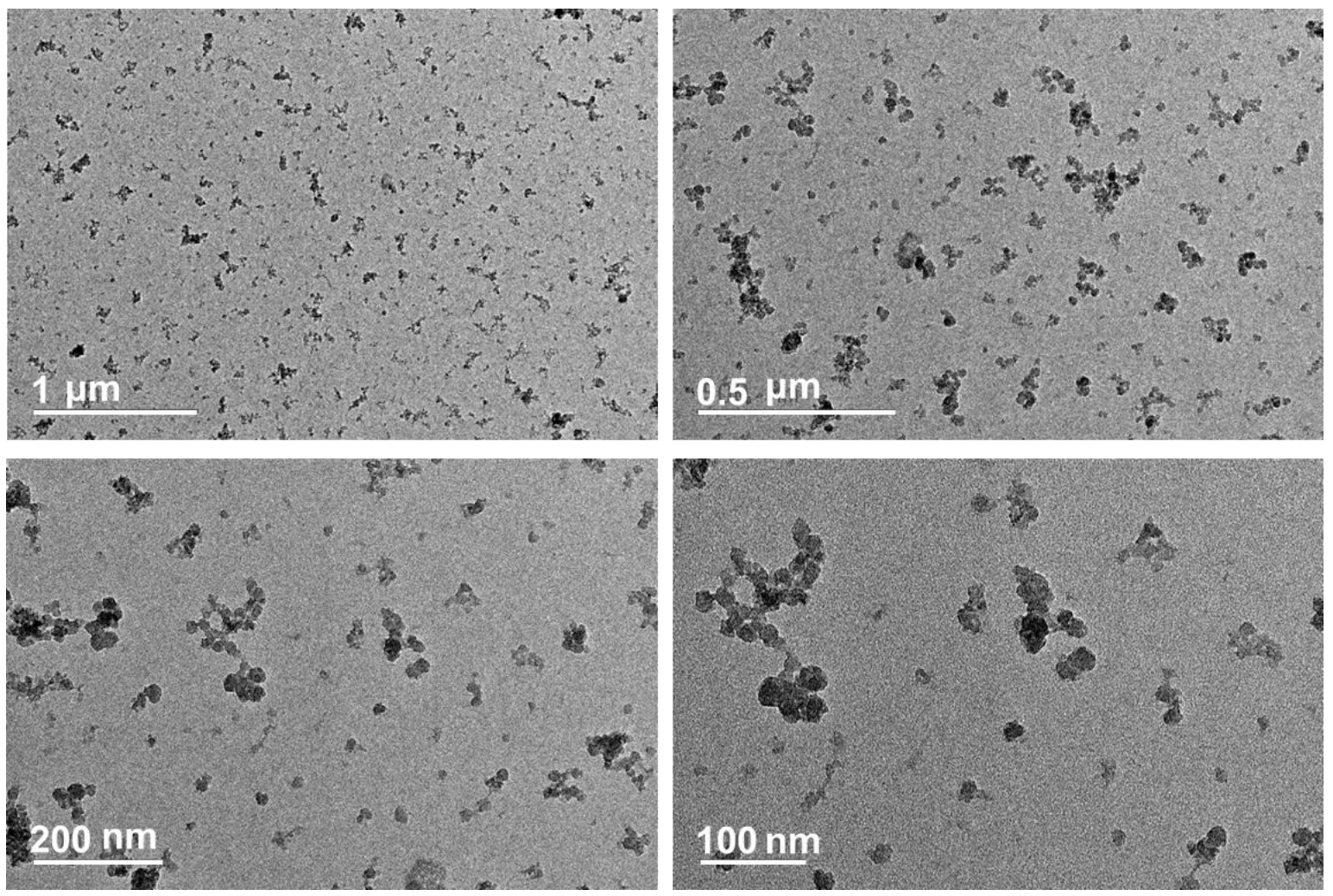

Figure S9. TEM images under different magnifications of MIL-101(Cr)- $\mathrm{NH}_{2}$ nanoparticles synthesized at $140{ }^{\circ} \mathrm{C}$ for $24 \mathrm{~h}$ using an $\mathrm{HCl}$ modulator with an $\mathrm{HCl} / \mathrm{H}_{2} \mathrm{~N}-\mathrm{H}_{2} \mathrm{BDC}$ molar ratio of 0.5 . Note that this figure is identical to Figure S3 but is included here to align with the analogous molar ratio experiments in Figures S8 and S10. 

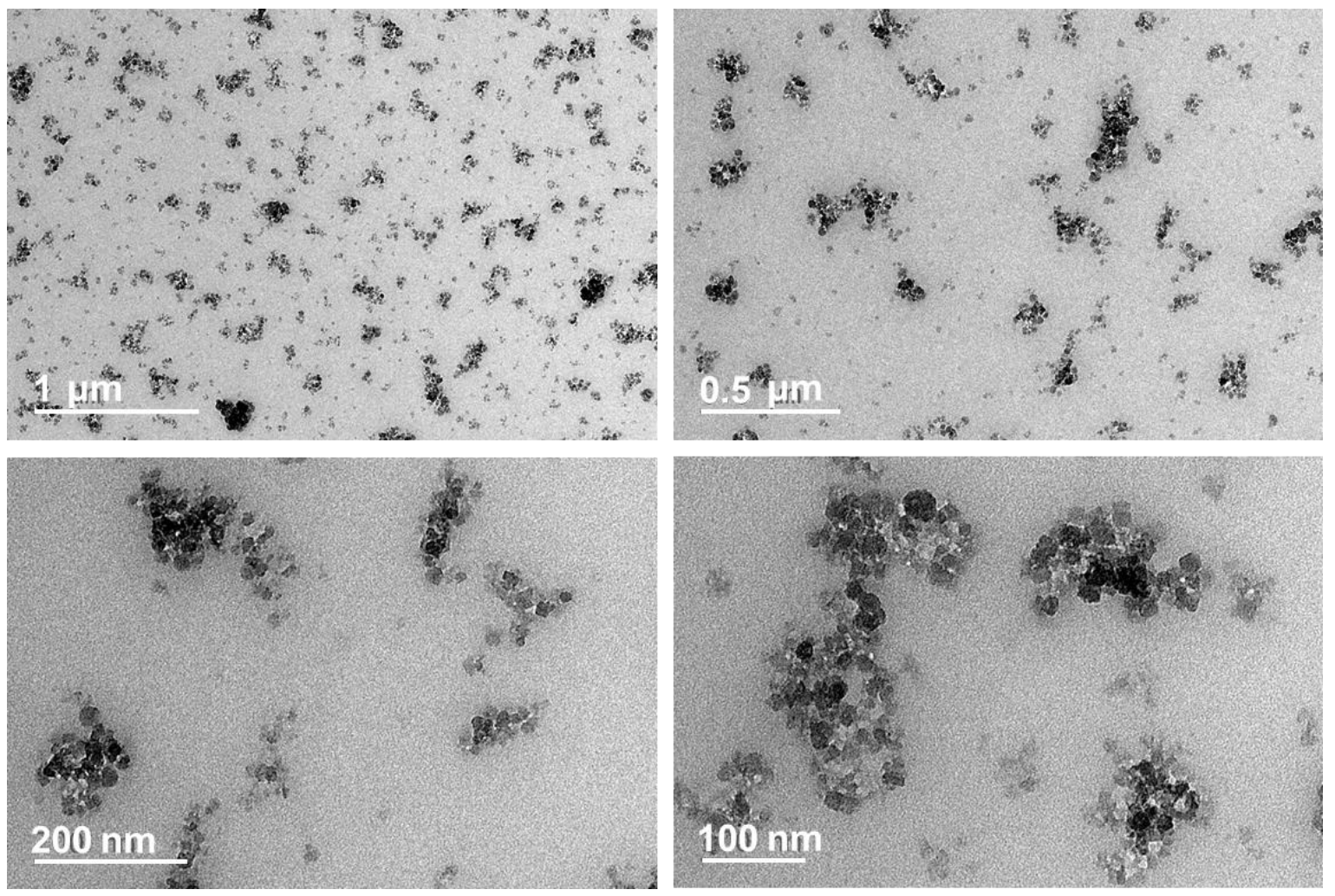

Figure S10. TEM images under different magnifications of MIL-101(Cr)- $\mathrm{NH}_{2}$ nanoparticles synthesized at $140{ }^{\circ} \mathrm{C}$ for $24 \mathrm{~h}$ using an $\mathrm{HCl}$ modulator with an $\mathrm{HCl} / \mathrm{H}_{2} \mathrm{~N}-\mathrm{H}_{2} \mathrm{BDC}$ molar ratio of 1.0 . 
(a)

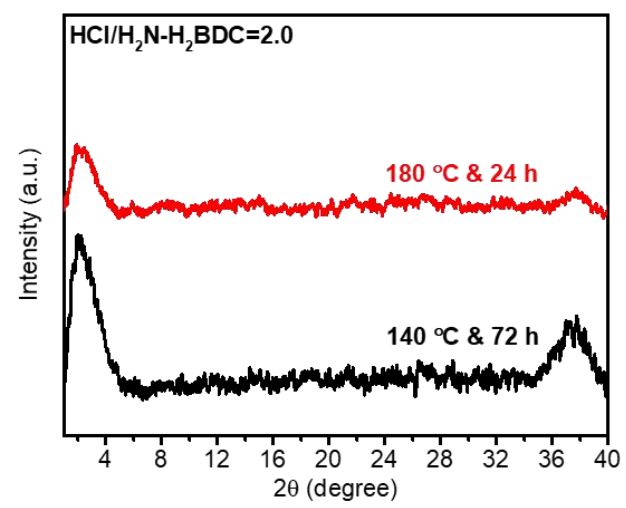

(c)

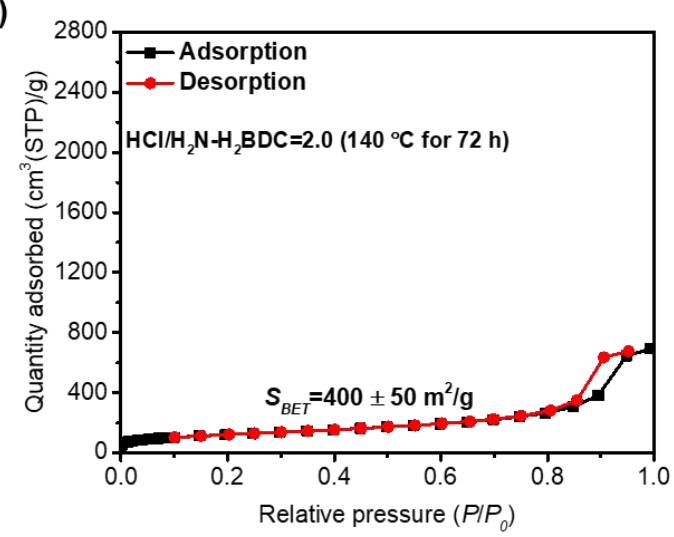

(b)
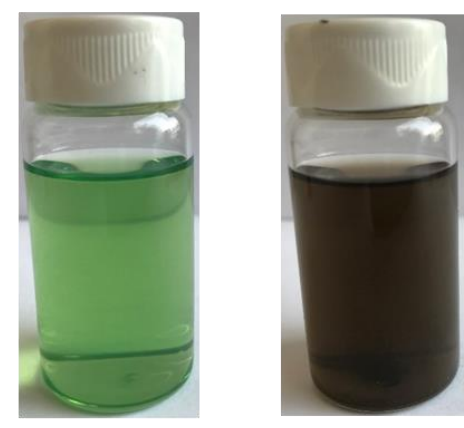

$140{ }^{\circ} \mathrm{C}$ for $72 \mathrm{~h}$

$180^{\circ} \mathrm{C}$ for $24 \mathrm{~h}$

(d)

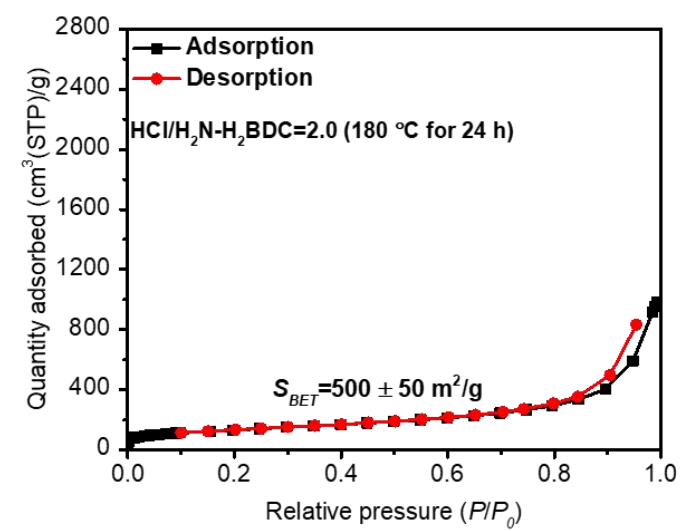

Figure S11. Powder XRD patterns (a), ethanol suspension (b), and $\mathrm{N}_{2}$ adsorption-desorption isotherms at $77 \mathrm{~K}$ with the calculated BET surface areas (c, d) of MIL-101(Cr)- $\mathrm{NH}_{2}$ synthesized at $140{ }^{\circ} \mathrm{C}$ for $72 \mathrm{~h}$ and $180{ }^{\circ} \mathrm{C}$ for $24 \mathrm{~h}$ using an $\mathrm{HCl}$ modulator with an $\mathrm{HCl} / \mathrm{H}_{2} \mathrm{~N}$ $\mathrm{H}_{2} \mathrm{BDC}$ molar ratio of 2.0 , respectively. 

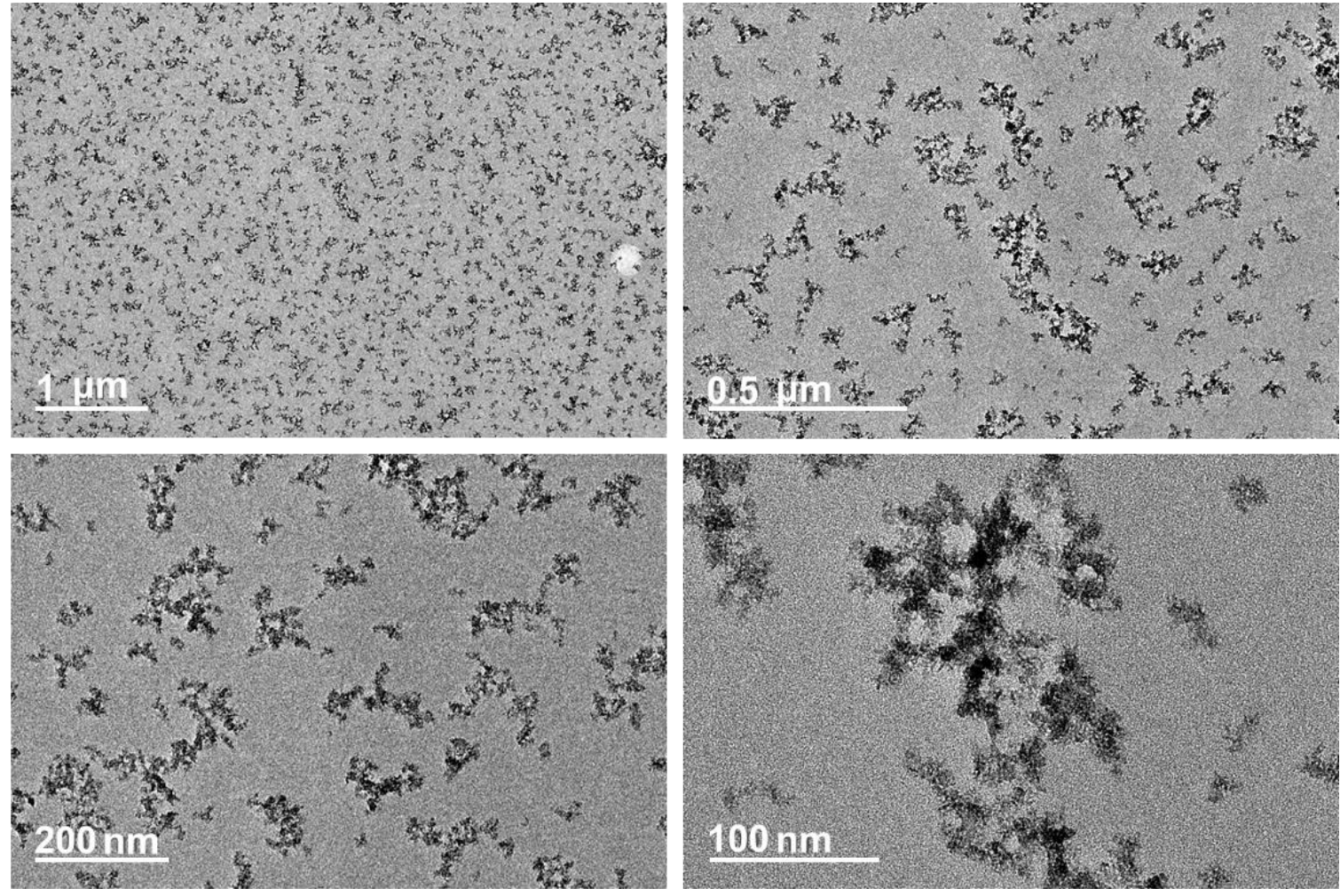

Figure S12. TEM images under different magnifications of MIL-101(Cr)- $\mathrm{NH}_{2}$ nanoparticles synthesized at $140{ }^{\circ} \mathrm{C}$ for $72 \mathrm{~h}$ using an $\mathrm{HCl}$ modulator with an $\mathrm{HCl} / \mathrm{H}_{2} \mathrm{~N}-\mathrm{H}_{2} \mathrm{BDC}$ molar ratio of 2.0 . 

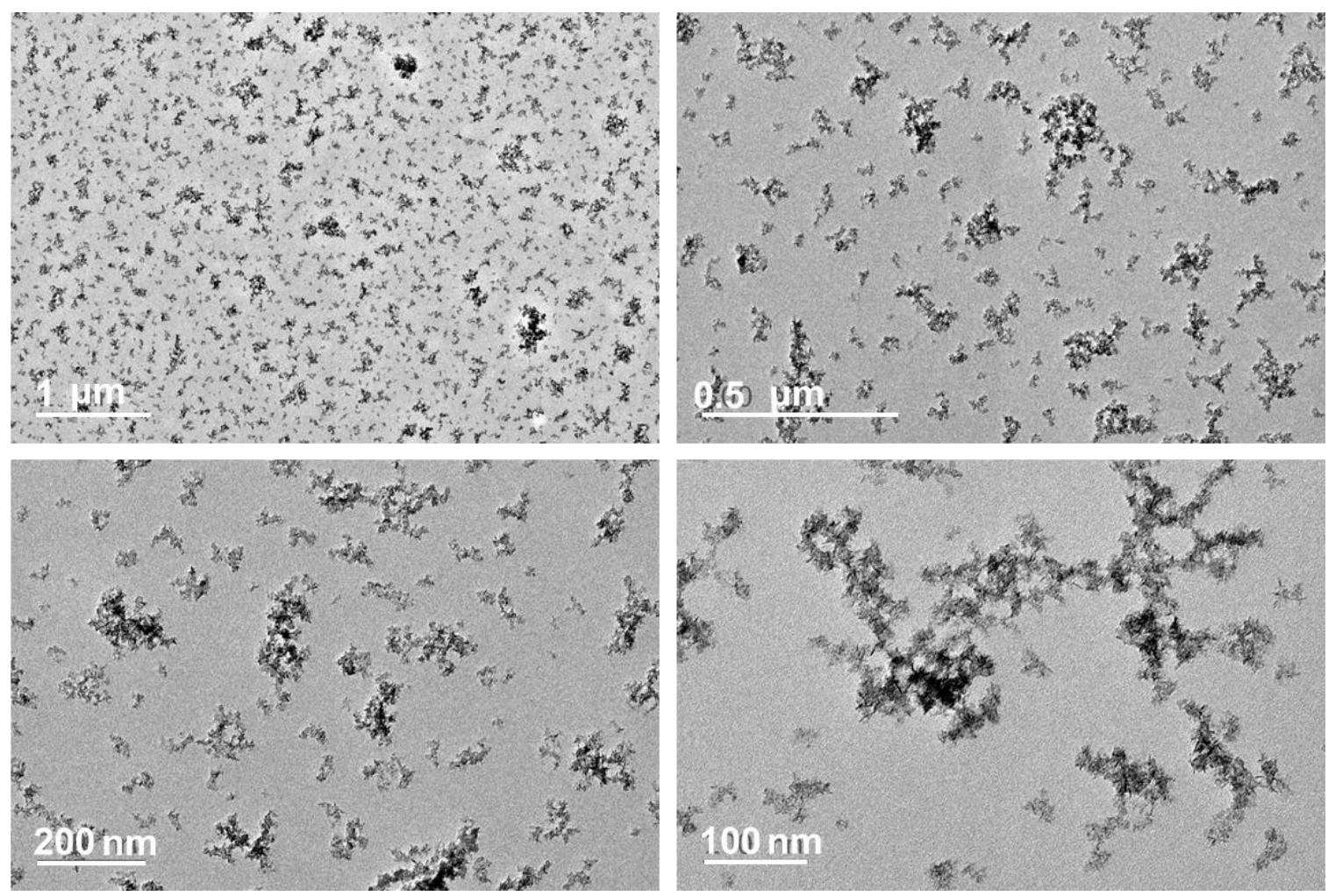

Figure S13. TEM images under different magnifications of MIL-101(Cr)- $\mathrm{NH}_{2}$ nanoparticles synthesized at $180{ }^{\circ} \mathrm{C}$ for $24 \mathrm{~h}$ using an $\mathrm{HCl}$ modulator with an $\mathrm{HCl} / \mathrm{H}_{2} \mathrm{~N}-\mathrm{H}_{2} \mathrm{BDC}$ molar ratio of 2.0 . 
(a)

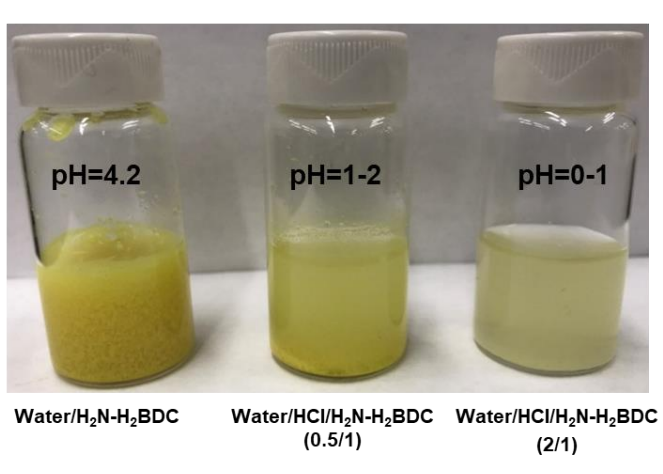

(c)

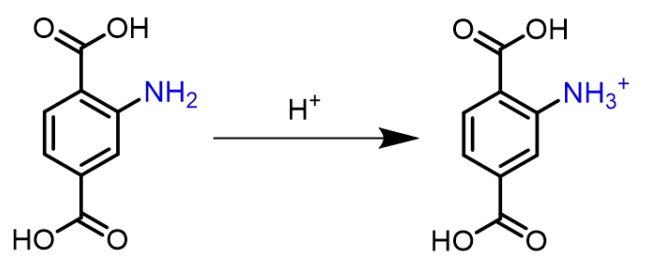

(b)

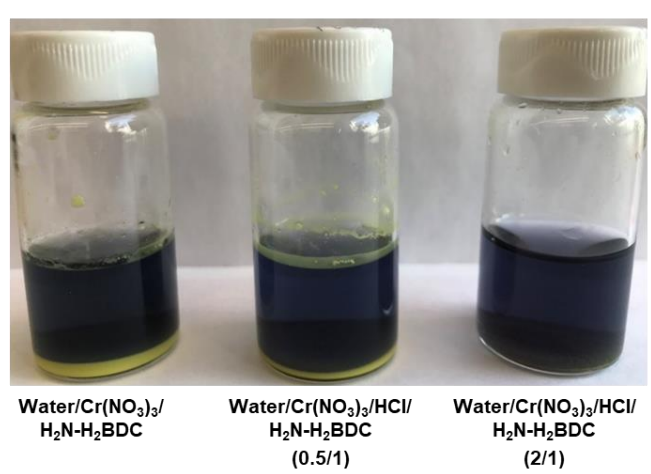

pKa values of the carboxylic acids of the $\mathrm{H}_{2} \mathrm{~N}-\mathrm{H}_{2} \mathrm{BDC}$ ligand are $\sim 3.5$ and 4.4 ; the isoelectric point is at $\mathrm{pH}$ of $4-5$.

Figure S14. Images and $\mathrm{pH}$ values of water/ $\mathrm{HCl} / \mathrm{H}_{2} \mathrm{~N}-\mathrm{H}_{2} \mathrm{BDC}$ mixtures (a), water $/ \mathrm{Cr}\left(\mathrm{NO}_{3}\right)_{3} / \mathrm{HCl} / \mathrm{H}_{2} \mathrm{~N}-\mathrm{H}_{2} \mathrm{BDC}$ mixtures with different $\mathrm{HCl} / \mathrm{H}_{2} \mathrm{~N}-\mathrm{H}_{2} \mathrm{BDC}$ molar ratios indicated in parentheses (b), and the schematic for protonation of the amine group on $\mathrm{H}_{2} \mathrm{~N}$ $\mathrm{H}_{2} \mathrm{BDC}$ ligand by acid (c). 

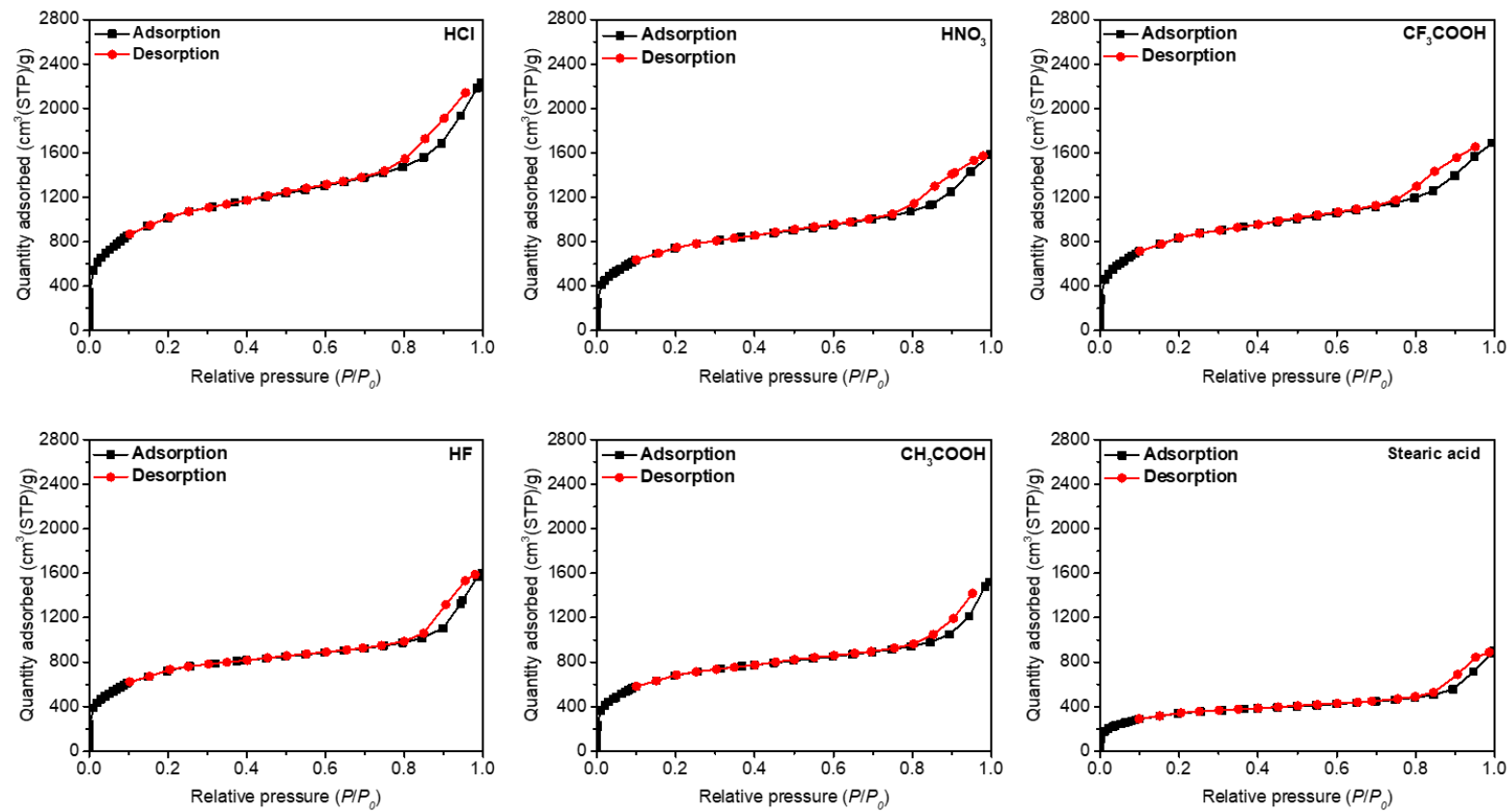

Figure S15. $\mathrm{N}_{2}$ adsorption-desorption isotherms at $77 \mathrm{~K}$ for MIL-101(Cr)- $\mathrm{NH}_{2}$ synthesized at $140{ }^{\circ} \mathrm{C}$ for $24 \mathrm{~h}$ using different acids as the modulators. The molar ratio of each acid to $\mathrm{H}_{2} \mathrm{~N}$ $\mathrm{H}_{2} \mathrm{BDC}$ is 0.5 . 

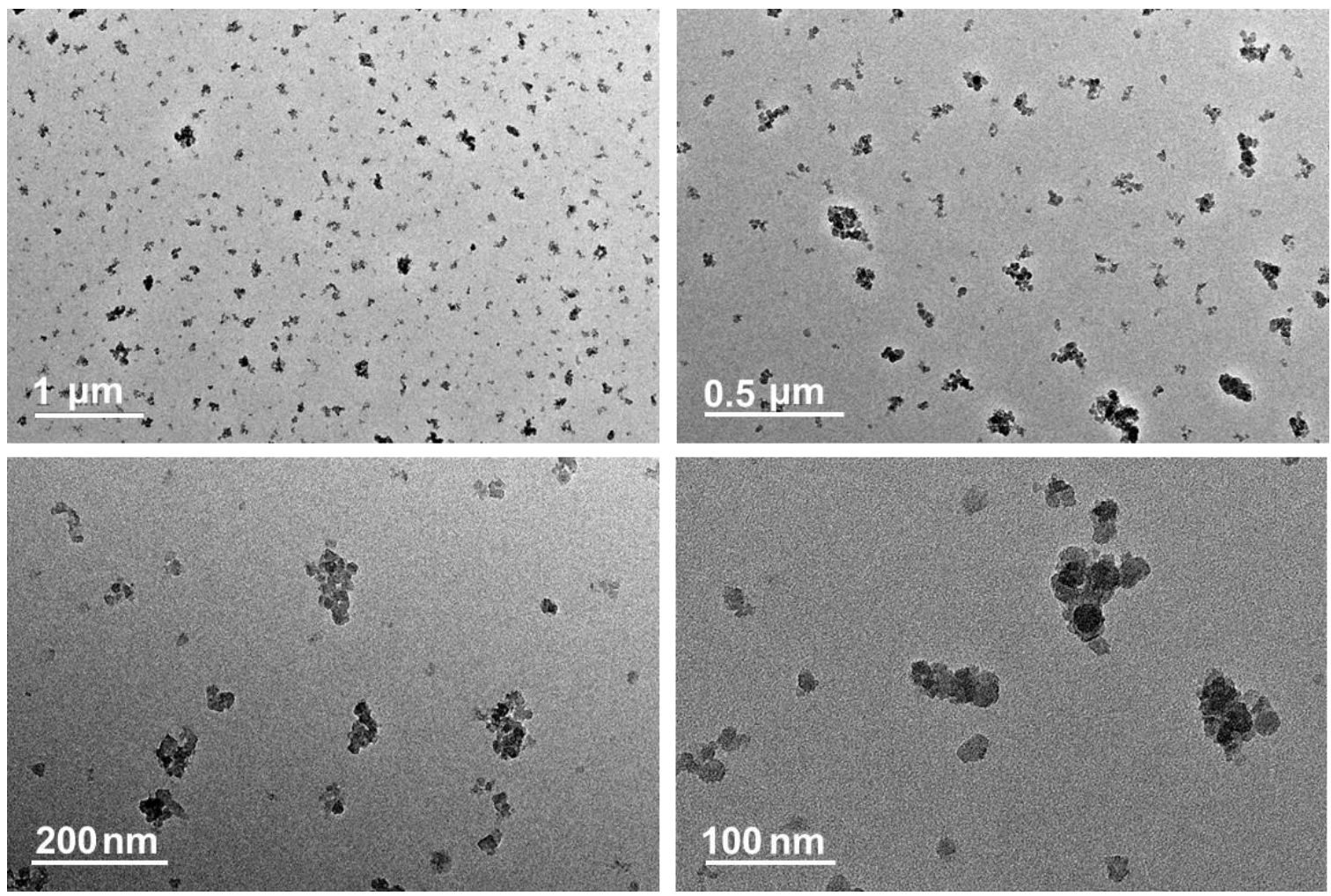

Figure S16. TEM images under different magnifications of MIL-101(Cr)-NH2 nanoparticles synthesized at $140{ }^{\circ} \mathrm{C}$ for $24 \mathrm{~h}$ using an $\mathrm{HNO}_{3}$ modulator with an $\mathrm{HNO}_{3} / \mathrm{H}_{2} \mathrm{~N}-\mathrm{H}_{2} \mathrm{BDC}$ molar ratio of 0.5 . 

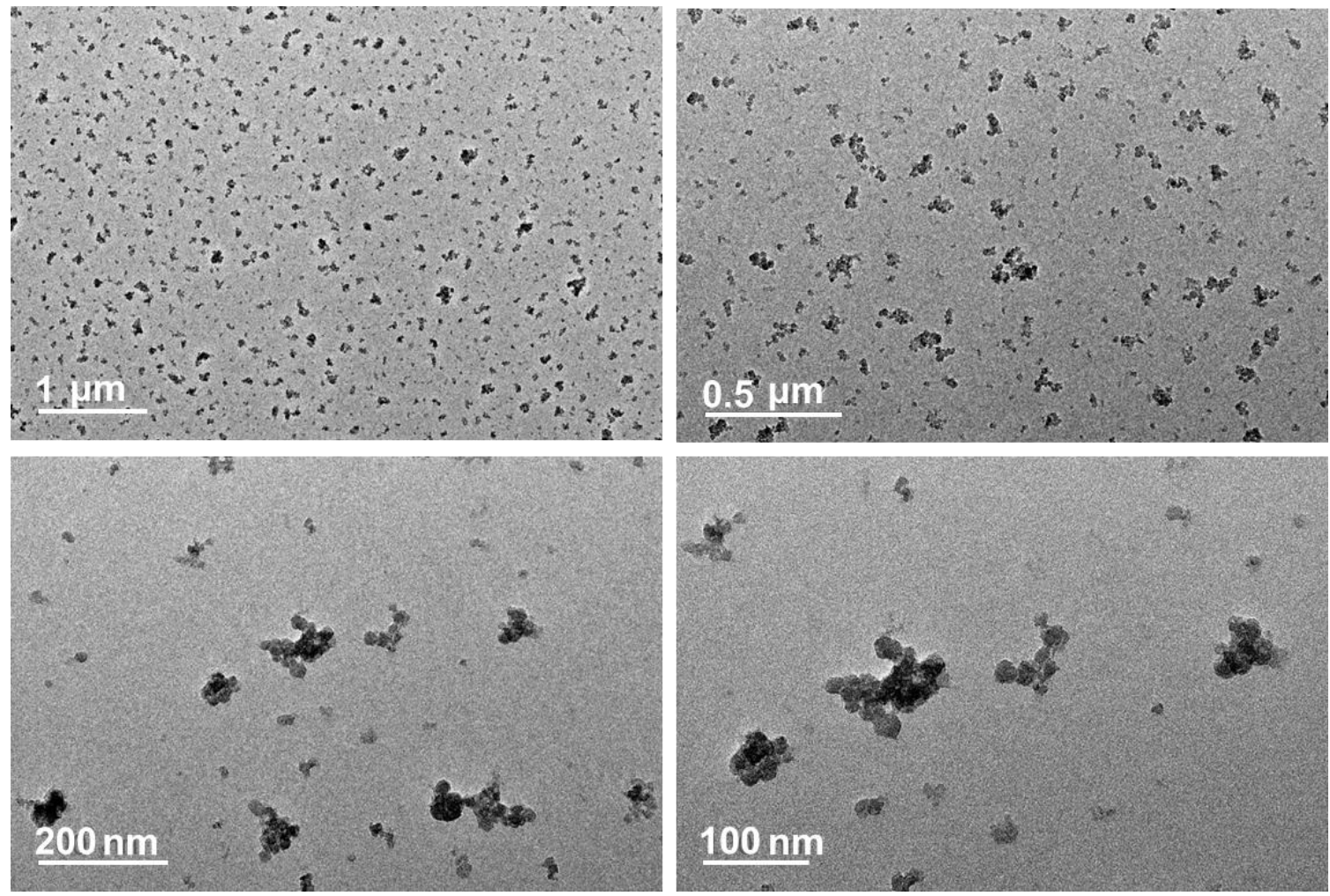

Figure S17. TEM images under different magnifications of MIL-101(Cr)- $\mathrm{NH}_{2}$ nanoparticles synthesized at $140{ }^{\circ} \mathrm{C}$ for $24 \mathrm{~h}$ using a $\mathrm{CF}_{3} \mathrm{COOH}$ modulator with a $\mathrm{CF}_{3} \mathrm{COOH} / \mathrm{H}_{2} \mathrm{~N}-\mathrm{H}_{2} \mathrm{BDC}$ molar ratio of 0.5 . 

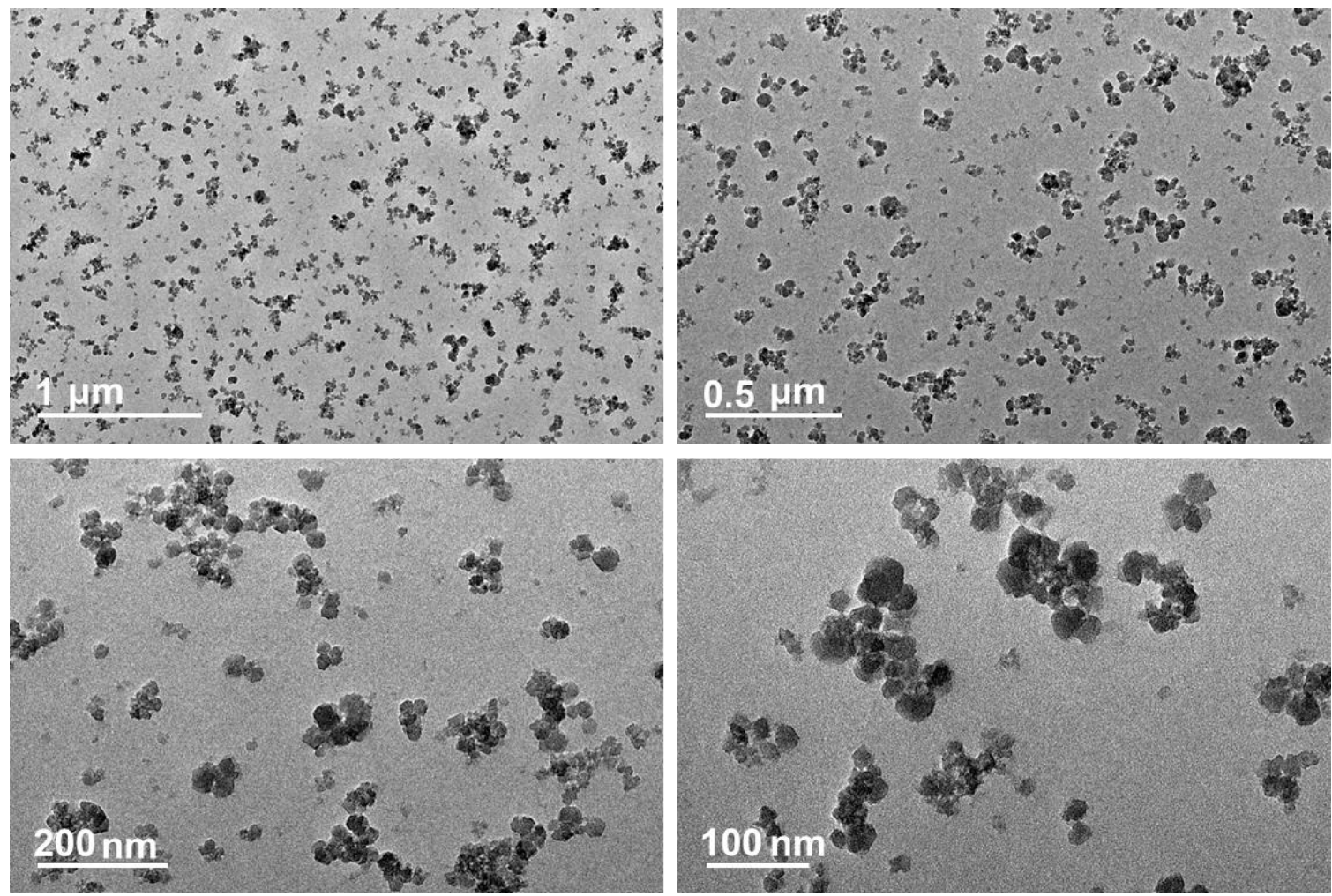

Figure S18. TEM images under different magnifications of MIL-101(Cr)- $\mathrm{NH}_{2}$ nanoparticles synthesized at $140{ }^{\circ} \mathrm{C}$ for $24 \mathrm{~h}$ using an $\mathrm{HF}$ modulator with an $\mathrm{HF} / \mathrm{H}_{2} \mathrm{~N}-\mathrm{H}_{2} \mathrm{BDC}$ molar ratio of 0.5 . 

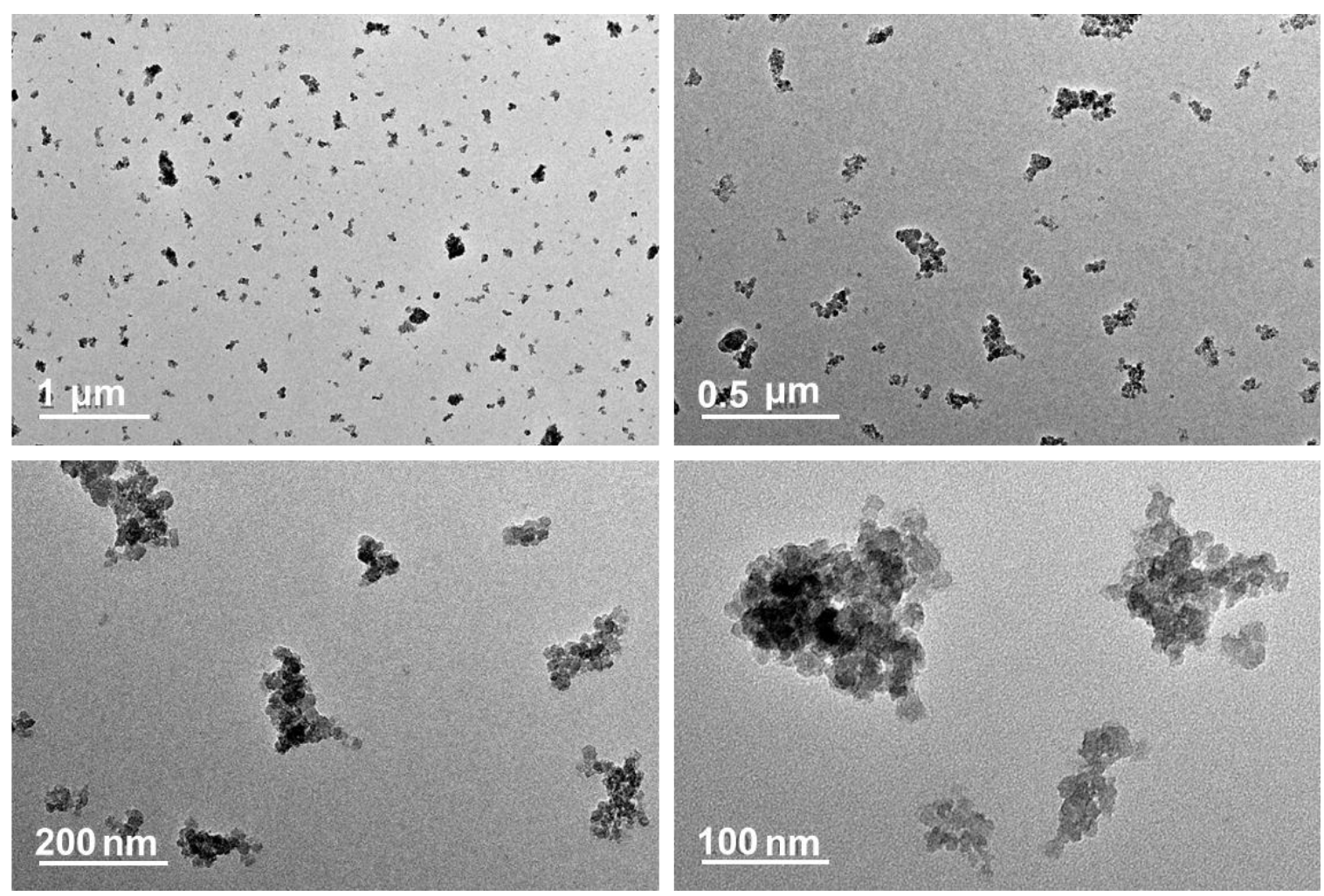

Figure S19. TEM images under different magnifications of MIL-101(Cr)- $\mathrm{NH}_{2}$ nanoparticles synthesized at $140{ }^{\circ} \mathrm{C}$ for $24 \mathrm{~h}$ using a $\mathrm{CH}_{3} \mathrm{COOH}$ modulator with a $\mathrm{CH}_{3} \mathrm{COOH} / \mathrm{H}_{2} \mathrm{~N}-\mathrm{H}_{2} \mathrm{BDC}$ molar ratio of 0.5 . 

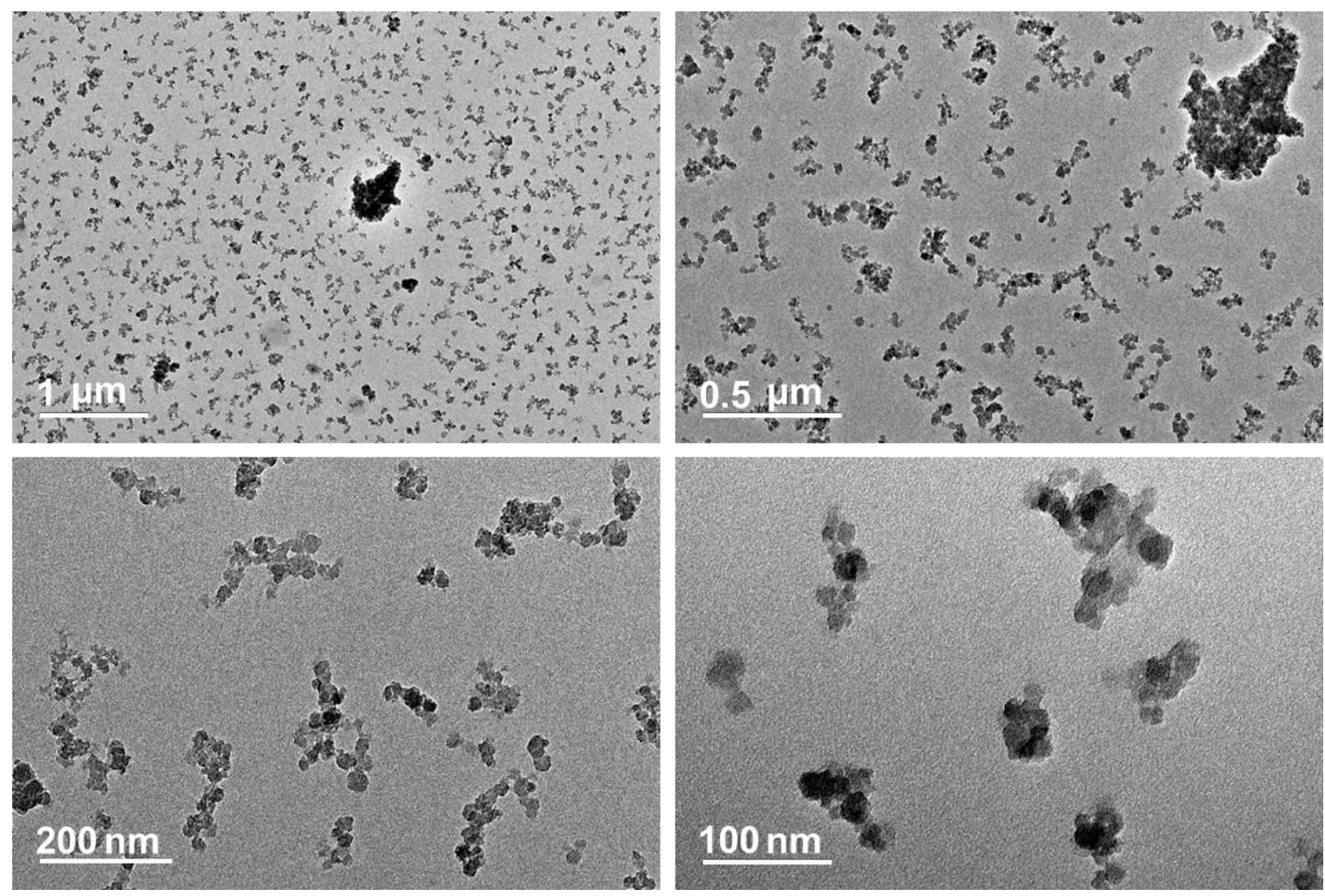

Figure S20. TEM images under different magnifications of MIL-101(Cr)- $\mathrm{NH}_{2}$ nanoparticles synthesized at $140{ }^{\circ} \mathrm{C}$ for $24 \mathrm{~h}$ using a stearic acid modulator with a stearic acid/ $\mathrm{H}_{2} \mathrm{~N}-\mathrm{H}_{2} \mathrm{BDC}$ molar ratio of 0.5 . 


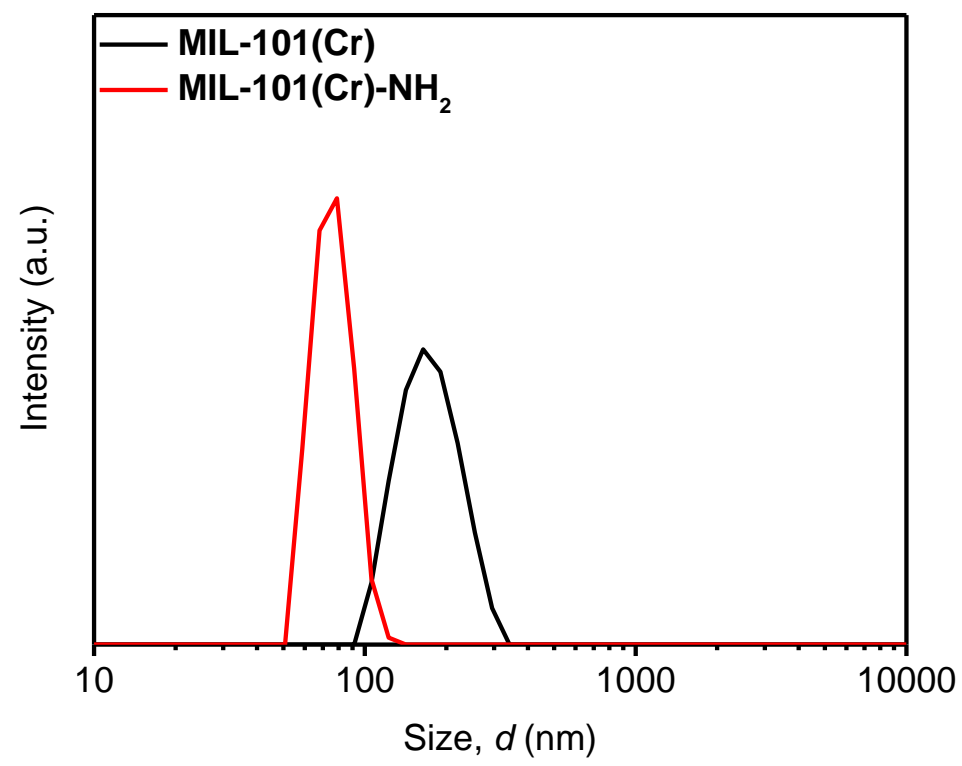

Figure S21. Dynamic light scattering (DLS) particle size distributions for the MIL-101(Cr) benchmark and MIL-101(Cr)- $\mathrm{NH}_{2}$ synthesized at $140{ }^{\circ} \mathrm{C}$ for $24 \mathrm{~h}$ using an $\mathrm{HCl}$ modulator with an $\mathrm{HCl} / \mathrm{H}_{2} \mathrm{~N}-\mathrm{H}_{2} \mathrm{BDC}$ molar ratio of 0.5 . 


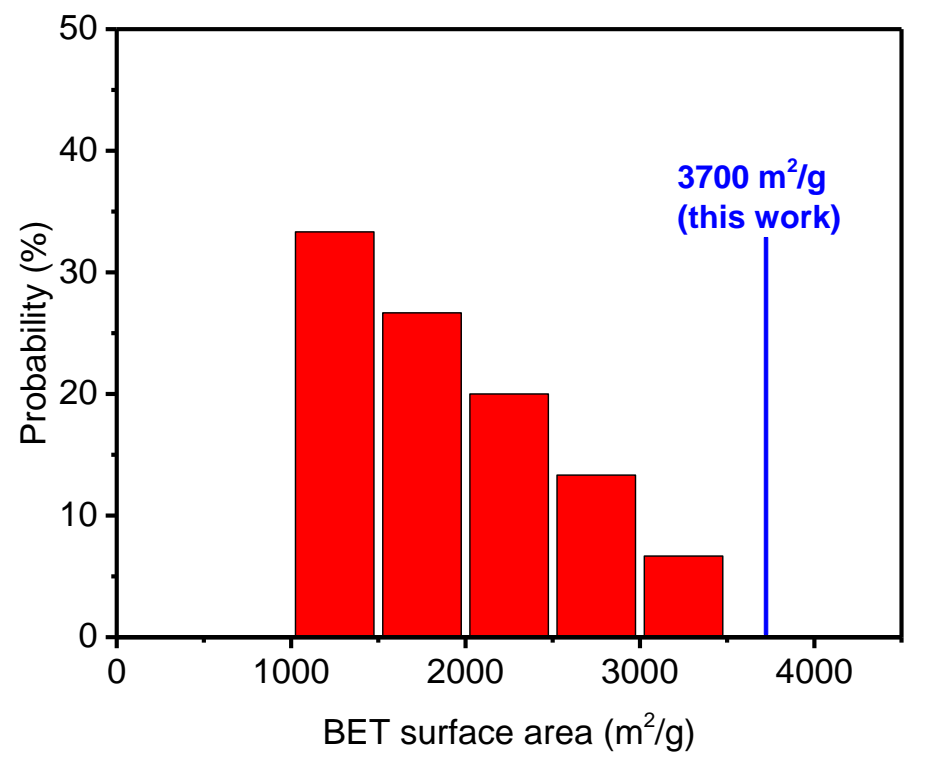

Figure S22. Histogram of the experimentally reported BET surface areas for MIL-101(Cr)$\mathrm{NH}_{2} \cdot{ }^{6-18}$ 

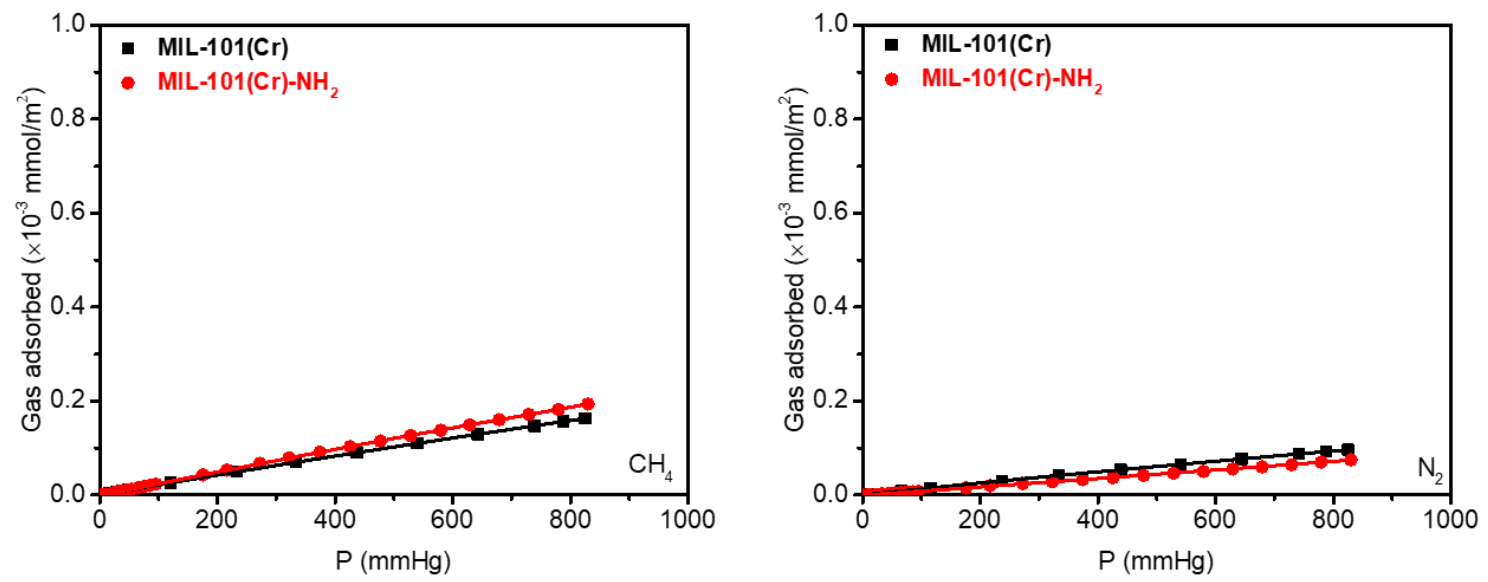

Figure S23. $\mathrm{CH}_{4}$ and $\mathrm{N}_{2}$ adsorption isotherms on a per unit internal surface area basis at 308 K for MIL-101(Cr)-NH2 and the parent MIL-101(Cr) benchmark. Points are experimental data, and solid lines are the fitted curves using the Langmuir-Freundlich (L-F) model. 

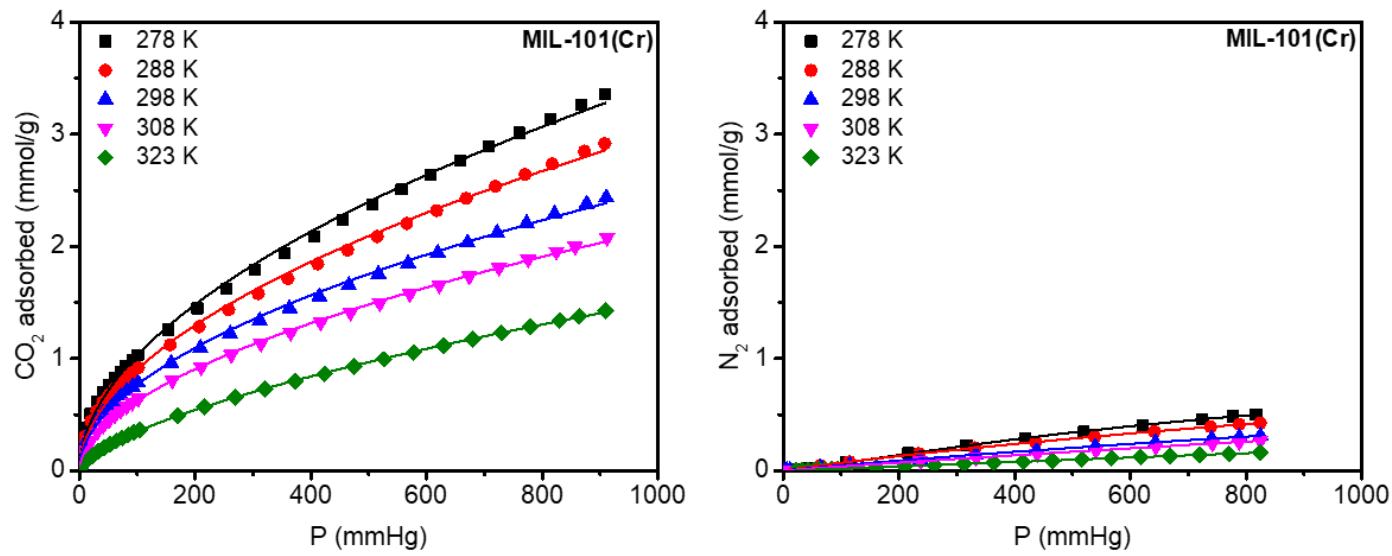

Figure S24. $\mathrm{CO}_{2}$ and $\mathrm{N}_{2}$ adsorption isotherms for the parent MIL-101(Cr) benchmark measured from $278 \mathrm{~K}$ to $323 \mathrm{~K}$. Points are experimental data, and solid lines are the fitted curves using the Langmuir-Freundlich (L-F) model. 
Table S1. Summary of the synthesis conditions for MIL-101(Cr)- $\mathrm{NH}_{2}$ nanoparticles in water using different acidic modulators.

\begin{tabular}{|c|c|c|c|c|c|c|c|}
\hline ID & $\begin{array}{c}\mathrm{Cr}\left(\mathrm{NO}_{3}\right)_{3} \\
(\mathrm{mmol})\end{array}$ & $\begin{array}{l}\mathrm{H}_{2} \mathrm{~N}-\mathrm{H}_{2} \mathrm{BDC} \\
(\mathrm{mmol})\end{array}$ & $\begin{array}{r}\mathrm{H}_{2} \mathrm{O} \\
(\mathrm{ml})\end{array}$ & $\begin{array}{c}\text { Temperature } \\
\left({ }^{\circ} \mathrm{C}\right)\end{array}$ & $\begin{array}{c}\text { Time } \\
\text { (h) }\end{array}$ & $\begin{array}{c}\mathrm{Acid} / \mathrm{H}_{2} \mathrm{~N}-\mathrm{H}_{2} \mathrm{BDC} \\
\text { molar ratio }\end{array}$ & Acid \\
\hline \multirow{14}{*}{$\mathrm{MIL}-101(\mathrm{Cr})-\mathrm{NH}_{2}$} & 0.63 & 0.63 & 10 & 120 & 24 & $0.5 / 1$ & \multirow{9}{*}{$\mathrm{HCl}$} \\
\hline & 0.63 & 0.63 & 10 & 140 & 24 & 0 & \\
\hline & 0.63 & 0.63 & 10 & 140 & 24 & $0.25 / 1$ & \\
\hline & 0.63 & 0.63 & 10 & 140 & 24 & $0.5 / 1$ & \\
\hline & 0.63 & 0.63 & 10 & 140 & 24 & $1 / 1$ & \\
\hline & 0.63 & 0.63 & 10 & 140 & 72 & $1 / 1$ & \\
\hline & 0.63 & 0.63 & 10 & 140 & 72 & $2 / 1$ & \\
\hline & 0.63 & 0.63 & 10 & 180 & 24 & $2 / 1$ & \\
\hline & 0.63 & 0.63 & 10 & 160 & 24 & $0.5 / 1$ & \\
\hline & 0.63 & 0.63 & 10 & 140 & 24 & $0.5 / 1$ & $\mathrm{HNO}_{3}$ \\
\hline & 0.63 & 0.63 & 10 & 140 & 24 & $0.5 / 1$ & $\mathrm{CF}_{3} \mathrm{COOH}$ \\
\hline & 0.63 & 0.63 & 10 & 140 & 24 & $0.5 / 1$ & $\mathrm{HF}$ \\
\hline & 0.63 & 0.63 & 10 & 140 & 24 & $0.5 / 1$ & $\mathrm{CH}_{3} \mathrm{COOH}$ \\
\hline & 0.63 & 0.63 & 10 & 140 & 24 & $0.5 / 1$ & Stearic acid \\
\hline
\end{tabular}


Table S2. Single gas ideal adsorption selectivity of the parent MIL-101(Cr) benchmark and MIL-101(Cr)-NH 2 at 308K.

\begin{tabular}{lcccc}
\hline & \multicolumn{4}{c}{ Ideal selectivity } \\
\cline { 2 - 5 } MOF ID & \multicolumn{2}{c}{$\mathbf{P}=\mathbf{7 5} \mathbf{~ m m H g}$} & \multicolumn{2}{c}{$\mathbf{P}=\mathbf{7 5 0} \mathbf{~ m m H g}$} \\
\cline { 2 - 4 } & $11.6 \pm 0.5$ & $19.6 \pm 1.2$ & $4.3 \pm 0.7$ & $7.5 \pm 0.5$ \\
\hline MIL-101(Cr) & $10.6 \pm 0.8$ & $32.5 \pm 1.0$ & $4.5 \pm 0.5$ & $12.4 \pm 0.9$ \\
MIL-101(Cr)-NH & $\mathbf{C O}_{2} / \mathbf{C H}_{\mathbf{2}}$ & $\mathbf{N}_{\mathbf{2}}$ & $\mathbf{N}_{\mathbf{2}}$ \\
\hline $\begin{array}{l}\text { The ideal selectivity was calculated from the single gas adsorption isotherms by dividing } \\
\text { the } \mathrm{CO}_{2} \text { uptake by that of the } \mathrm{CH}_{4} \text { or } \mathrm{N}_{2} \text { uptake. }\end{array}$ \\
\hline
\end{tabular}


Table S3. IAST-calculated selectivities for a $\mathrm{CO}_{2}: \mathrm{N}_{2}$ binary mixture with a 15:85 mixture composition of the parent MIL-101(Cr) benchmark and MIL-101(Cr)-NH 2 at $323 \mathrm{~K}$.

\begin{tabular}{|c|c|c|c|}
\hline \multirow{2}{*}{ MOF ID } & \multicolumn{3}{|c|}{ Selectivity factor } \\
\hline & $20 \mathrm{mmHg}$ & $112 \mathrm{mmHg}$ & $750 \mathrm{mmHg}$ \\
\hline $\operatorname{MIL-101(Cr)~}$ & 91.2 & 39.0 & 17.1 \\
\hline $\mathrm{MIL}-101(\mathrm{Cr})-\mathrm{NH}_{2}$ & 122.0 & 78.8 & 48.6 \\
\hline \multicolumn{4}{|c|}{ The $\mathrm{CO}_{2}: \mathrm{N}_{2}$ binary mixture with a $15: 85$ mixture composition is similar to that of flue gas. } \\
\hline
\end{tabular}




\section{REFERENCES}

(1) Han, G.; Qian, Q.; Rodriguez, K. M.; Smith, Z. P. Hydrothermal Synthesis of Sub-20 nm Amine-Functionalized MIL-101(Cr) Nanoparticles with High Surface Area and Enhanced $\mathrm{CO}_{2}$ Uptake. Ind. Eng. Chem. Res. 2020, 59, 7888-7900.

(2) Zhou, X.; Huang, W.; Miao, J.; Xia, Q.; Zhang, Z.; Wang, H.; Li, Z. Enhanced Separation Performance of A Novel Composite Material Gro@MIL-101 for $\mathrm{CO}_{2} / \mathrm{CH}_{4}$ Binary Mixture. Chem. Eng. J. 2015, 266, 339-344.

(3) Chen, C.; Feng, N.; Guo, Q.; Li, Z.; Li, X.; Ding, J.; Wang, L.; Wan, H.; Guan, G. Template-Directed Fabrication of MIL-101(Cr)/Mesoporous Silica Composite: Layer-Packed Structure and Enhanced Performance for $\mathrm{CO}_{2}$ Capture. J. Colloid Interface Sci. 2018, 513, 891-902.

(4) Kayal, S.; Chakraborty, A. Impact of Alkali-Metal Impregnation on MIL-101 (Cr) Metal-Organic Frameworks for $\mathrm{CH}_{4}$ and $\mathrm{CO}_{2}$ Adsorption Studies. ChemPhysChem 2018, 19, $3158-3165$.

(5) McDonald, T. M.; D’Alessandro, D. M.; Krishna, R.; Long, J. R. Enhanced Carbon Dioxide Capture upon Incorporation of N,N'-Dimethylethylenediamine in the Metal-Organic Framework CuBTTri. Chem. Sci. 2011, 2, 2022-2028.

(6) Lin, Y.; Kong, C.; Chen, L. Direct Synthesis of Amine-Functionalized MIL-101(Cr) Nanoparticles and Application for $\mathrm{CO}_{2}$ Capture. RSC Adv. 2012, 2, 6417-6419.

(7) Huang, X.; Lu, J.; Wang, W.; Wei, X.; Ding, J. Experimental and Computational Investigation of $\mathrm{CO}_{2}$ Capture on Amine Grafted Metal-Organic Framework NH $2-\mathrm{MIL}-101$. Appl. Surf. Sci. 2016, 371, 307-313.

(8) Zhou, F.; Zhou, J.; Gao, X.; Kong, C.; Chen, L. Facile Synthesis of MOFs with Uncoordinated Carboxyl Groups for Selective $\mathrm{CO}_{2}$ Capture via Postsynthetic Covalent Modification. RSC Adv. 2017, 7, 3713-3719. 
(9) Jiang, D.; Keenan, L. L.; Burrows, A. D.; Edler, K. J. Synthesis and Post-Synthetic Modification of MIL-101(Cr)- $\mathrm{NH}_{2}$ via A Tandem Diazotisation Process. Chem. Commun. 2012, 48, 12053-12055.

(10) Yan, Q.; Lin, Y.; Kong, C.; Chen, L. Remarkable $\mathrm{CO}_{2} / \mathrm{CH}_{4}$ Selectivity and $\mathrm{CO}_{2}$ Adsorption Capacity Exhibited by Polyamine-Decorated Metal-Organic Framework Adsorbents. Chem. Commun. 2013, 49, 6873-6875.

(11) Li, X.; Mao, Y.; Leng, K.; Ye, G.; Sun, Y.; Xu, W. Synthesis of Amino-Functionalized MIL-101(Cr) with Large Surface Area. Mater. Lett. 2017, 197, 192-195.

(12) Liu, B.; Peng, Y.; Chen, Q. Adsorption of N/S-Heteroaromatic Compounds from Fuels by Functionalized MIL-101(Cr) Metal-Organic Frameworks: The Impact of Surface Functional Groups. Energ. Fuel. 2016, 30, 5593-5600.

(13) Bernt, S.; Guillerm, V.; Serreb, C.; Stock, N. Direct Covalent Post-Synthetic Chemical Modification of Cr-MIL-101 Using Nitrating Acid. Chem. Commun. 2011, 47, 2838-2840.

(14) Zhang, Y. W.; Li, Z.; Zhao, Q.; Zhou, Y. L.; Liu, H. W.; Zhang, X. X. A Facilely Synthesized Amino-Functionalized Metal-Organic Framework for Highly Specific and Efficient Enrichment of Glycopeptides. Chem. Commun. 2014, 50, 11504-11506.

(15) Wen, M.; Mori, K.; Kamegawa, T.; Yamashta, H. Amine-Functionalized MIL-101(Cr) with Imbedded Platinum Nanoparticles as A Durable Photocatalyst for Hydrogen Production from Water. Chem. Commun. 2014, 50, 11645-11648.

(16) Saikia, M.; Kaichev, V.; Saikia, L. Gold Nanoparticles Supported on Nanoscale AmineFunctionalized MIL-101(Cr) as A Highly Active Catalyst for Epoxidation of Styrene. RSC Adv. 2016, 6, 106856-106865.

(17) Wang, J.; Huang, X.; Gao, H.; Li, A.; Wang, C. Construction of CNT@Cr-MIL-101$\mathrm{NH}_{2}$ Hybrid Composite for Shape Stabilized Phase Change Materials with Enhanced Thermal Conductivity. Chem. Eng. J. 2018, 350, 164-172. 
(18) Bahadori, M.; Tangestaninejad, S.; Moghadam, M.; Mirkhani, V.; Mechler, A.; Mohammadpoor-Baltork, I.; Zadehahmadi, F. Metal Organic Framework-Supported NHeterocyclic Carbene Palladium Complex: A Highly Efficient and Reusable Heterogeneous Catalyst for Suzuki-Miyaura C-C Coupling Reaction. Microporous Mesoporous Mater. 2017, $253,102-111$. 